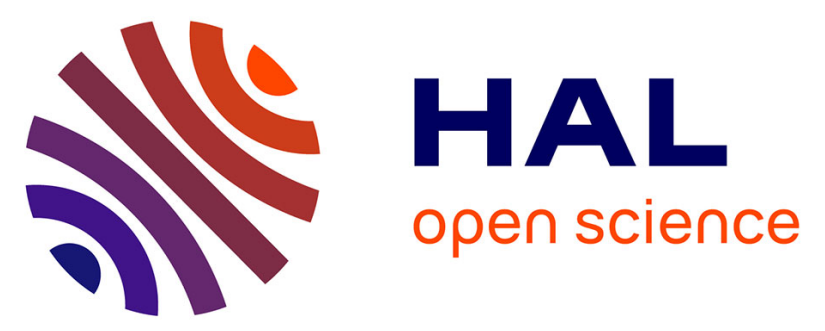

\title{
The role of the striatum in linguistic selection: Evidence from Huntington's disease and computational modeling
}

Maria Giavazzi, Robert Daland, Stefano Palminteri, Sharon Peperkamp, Pierre Brugieres, Charlotte Jacquemot, Catherine Schramm, Laurent Cleret de Langavant, Anne-Catherine Bachoud-Lévi

\section{To cite this version:}

Maria Giavazzi, Robert Daland, Stefano Palminteri, Sharon Peperkamp, Pierre Brugieres, et al.. The role of the striatum in linguistic selection: Evidence from Huntington's disease and computational modeling. Cortex, 2018, 109, pp.189-204. 10.1016/j.cortex.2018.08.031 . hal-02326550

\section{HAL Id: hal-02326550 https://hal.science/hal-02326550}

Submitted on 20 Nov 2020

HAL is a multi-disciplinary open access archive for the deposit and dissemination of scientific research documents, whether they are published or not. The documents may come from teaching and research institutions in France or abroad, or from public or private research centers.
L'archive ouverte pluridisciplinaire HAL, est destinée au dépôt et à la diffusion de documents scientifiques de niveau recherche, publiés ou non, émanant des établissements d'enseignement et de recherche français ou étrangers, des laboratoires publics ou privés. 


\section{Accepted Manuscript}

The role of the striatum in linguistic selection: Evidence from Huntington's disease and computational modeling

Maria Giavazzi, Robert Daland, Stefano Palminteri, Sharon Peperkamp, Pierre Brugières, Charlotte Jacquemot, Catherine Schramm, Laurent Cleret de Langavant,

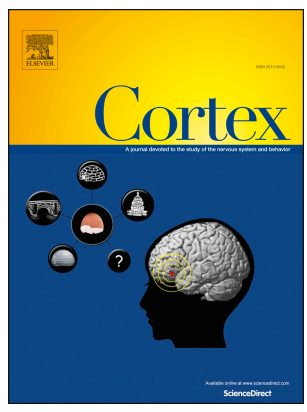
Anne-Catherine Bachoud -Lévi

PII:

S0010-9452(18)30283-1

DOI:

10.1016/j.cortex.2018.08.031

Reference: CORTEX 2403

To appear in: Cortex

Received Date: 15 December 2017

Revised Date: 4 July 2018

Accepted Date: 5 August 2018

Please cite this article as: Giavazzi M, Daland R, Palminteri S, Peperkamp S, Brugières $P$, Jacquemot C, Schramm C, Cleret de Langavant L, Bachoud -Lévi A-C, The role of the striatum in linguistic selection: Evidence from Huntington's disease and computational modeling, CORTEX (2018), doi: https://doi.org/10.1016/j.cortex.2018.08.031.

This is a PDF file of an unedited manuscript that has been accepted for publication. As a service to our customers we are providing this early version of the manuscript. The manuscript will undergo copyediting, typesetting, and review of the resulting proof before it is published in its final form. Please note that during the production process errors may be discovered which could affect the content, and all legal disclaimers that apply to the journal pertain. 


\section{TITLE}

2 The role of the striatum in linguistic selection:

3 Evidence from Huntington's disease and computational modeling

\section{Authors}

6 Maria Giavazzi ${ }^{1,2,3}$, Robert Daland ${ }^{4}$, Stefano Palminteri ${ }^{1,5}$, Sharon Peperkamp ${ }^{1,6}$, Pierre

7 Brugières $^{7}$, Charlotte Jacquemot ${ }^{1,2,3}$, Catherine Schramm ${ }^{1,2,3}$, Laurent Cleret de

8 Langavant ${ }^{1,2,3,8}$, Anne-Catherine Bachoud-Lévi ${ }^{1,2,3,8}$

9

\section{AfFiliations}

11 France.

${ }^{1}$ Département d'Etudes Cognitives, Ecole Normale Supérieure - PSL Research University, 29 rue d'Ulm, 75005 Paris, France.

${ }^{2}$ Equipe de NeuroPsychologie Interventionnelle, Institut National de la Santé et Recherche Médical (INSERM) U955, Equipe 01, 8 rue du Général Sarrail, 9400, Créteil, France.

${ }^{3}$ Université Paris Est, Faculté de Médecine, 8 rue du Général Sarrail, 9400, Créteil, France.

${ }^{4}$ UCLA Department of Linguistics, 3125 Campbell Hall, University of California, Los Angeles, CA 90095, United States

${ }^{5}$ Laboratoire de Neurosciences Cognitives (LNC), Institut National de la Santé et Recherche Médical (INSERM) U960, École Normale Supérieure (ENS), 29 rue d’Ulm, 75005 Paris, France. 
$26{ }^{6}$ Laboratoire de Sciences Cognitives et Psycholinguistique, ENS-EHESS-CNRS,

2729 rue d'Ulm, 75005 Paris, France.

28

$29{ }^{7}$ Service de Neuroradiologie, Hôpital Henri Mondor, AP-HP, 51 Avenue du Maréchal de 30 Lattre de Tassigny, 94010 Créteil, France.

31

32

${ }^{8}$ Centre de référence maladie de Huntington, Hôpital Henri Mondor, AP-HP, 8 rue du Général

33 Sarrail, 9400, Créteil, France.

34

35

Corresponding Author

36 Maria Giavazzi, Ph.D.

37 Département d'Etude Cognitives, Ecole Normale Supérieure

38 29, rue d'Ulm, Paris (75005)

39 France

40

41 email address: maria.giavazzi@ens.fr

42

43

44

45

46

47

48

49 


\section{RUNNING TITLE}

51 Role of the striatum in linguistic selection

52

\section{KEYWORDS}

54 Language, Huntington's disease, basal ganglia, brain mapping

55

56 HighLIGHTS

57 A specific deficit underlies the linguistic impairment of patients with striatal lesions

58 - Striatal lesions cause deficit in selection processes not in grammatical evaluation

59 - Striatum selects linguistic alternatives computed in cortical language areas

60 - Atrophy in dorsal striatum correlates with selection deficit in Huntington disease

61

62

63 


\section{AbSTRACT}

65 Though accumulating evidence indicates that the striatum is recruited during language 66 processing, the specific function of this subcortical structure in language remains to be elucidated. To answer this question, we used Huntington's disease as a model of striatal lesion. We investigated the morphological deficit of 30 early Huntington's disease patients with a novel linguistic task that can be modeled within an explicit theory of linguistic computation. Behavioral results reflected an impairment in HD patients on the linguistic task. two distinct lesion models, a selection deficit model and a grammatical deficit model. This analysis revealed that the impairment derives from an increased randomness in the process of selecting between grammatical alternatives, rather than from a disruption of grammatical knowledge per se. Voxel-based morphometry permitted to correlate this impairment to dorsal striatal degeneration. We thus show that the striatum holds a role in the selection of linguistic alternatives, just as in the selection of motor and cognitive programs.

\section{(8)}

(1)

0

\section{1} 2 3 4 5 


\section{INTRODUCTION}

91 Though research on the neural basis of language processing has mainly focused on cortical

92 structures and their connections (Fedorenko, Behr, \& Kanwisher, 2011; Friederici, 2012;

93 Friederici \& Gierhan, 2013; Hickok \& Poeppel, 2007), subcortical structures and connections

94 between cortical and subcortical systems are also part of the language network. The striatum

95 is one of the most important subcortical structures involved in language processing. Evidence

96 of striatal involvement in language was initially observed in neuropsychological studies of 97 patients with focal striatal lesions (Cambier, Elghozi, \& Strube, 1979; Cappa, Cavallotti,

Guidotti, Papagno, \& Vignolo, 1983; Damasio, Damasio, Rizzo, Varney, \& Gersh, 1982;

Demonet, 1997; Gronholm, Roll, Horne, Sundgren, \& Lindgren, 2016; Nadeau \& Crosson, 1997), and patients with neurodegenerative diseases causing striatal dysfunction, i.e.

101 Huntington's and Parkinson's disease (Douaud et al., 2006; Stoessl, Lehericy, \& Strafella, 2014). In a series of verb conjugation tasks Ullman and colleagues (Ullman, 2001, 2006;

Ullman et al., 1997) found that English speaking Huntington's Disease (HD) patients overregularize irregular verbs (e.g. *he runned instead of he ran) and produced doublesuffixations on regular verbs (e.g. walk-ed-ed). The authors interpret this deficit within a

106 dichotomic model of language processing (Pinker, 1997), which consists of a 'mental lexicon'

107 storing information, and a computational 'mental grammar' computing rules over stored 108 abstract representations (Nemeth et al., 2012; Ullman, 2004, 2006; Ullman et al., 1997). 109 Based on patients' deficits, the authors localize the neural correlates of the model's 110 components, attributing lexical processing to the medial temporal lobe network, and 111 grammatical processing to the fronto-striatal circuits. HD patients would thus be specifically 112 impaired with the processing of linguistic rules. Teichmann and colleagues conducted similar 113 experiments with French patients testing them on the production of future tense forms of non- 
114 existing (nonce) verbs (Teichmann et al., 2005; Teichmann et al., 2008). French has two

115 regular patterns for the formation of the future tense: a frequent default pattern (first 116 conjugation, e.g. manger-mangera) and a less frequent, non-default pattern (second and third 117 conjugation, e.g. dormir-dormira), also called 'subregular'. In addition, like English, French 118 also has a variety of highly restricted irregular alternatives (e.g. venir-viendra). The authors 119 found that HD patients over-applied the most frequent rule to items belonging to the less 120 frequent conjugation (e.g. saurentir -*saurentera, instead of saurentira). The authors 121 interpreted the results along Ullman's proposal. However, since the application of the default 122 rule was spared in first conjugation verbs, they characterized the deficit in HD as being 123 restricted to 'subregular' rules. In addition to this rule application learning deficit, De Diego124 Balaguer and colleagues observed a rule-learning deficit in a comparable sample of early 125 French Huntington's disease patients tested on the learning of a simplified artificial language 126 where words and rules could be extracted (De Diego-Balaguer et al., 2008). The authors also 127 report results from pre-manifest carriers of the HD mutation, whose performance was not 128 quantitatively different from the one of matched controls in the learning task, but who showed 129 a qualitative difference in the level of abstractedness of the acquired rule.

130 Within the neuropsychological literature, other experimental results suggest that, rather than 131 being recruited for rule learning and rule application, the striatum is needed at late processing 132 stages requiring selection and inhibition between competing alternatives (Copland et al., 133 2003; Garcia et al., 2017; Longworth, Keenan, Barker, Marslen-Wilson, \& Tyler, 2005; 134 Sambin et al., 2012) and syntactic reanalysis (Kotz, Frisch, von Cramon, \& Friederici, 2003). 135 Neuroimaging studies of healthy subjects also provide data compatible with this alternative 136 proposal. The left dorsal striatum in particular is activated in tasks requiring reanalysis of 137 ambiguous or incorrect sentences (Friederici \& Kotz, 2003; Mestres-Misse, Turner, \& 138 Friederici, 2012; Moro et al., 2001; Tettamanti et al., 2005). A role of the striatum in 
139 linguistic tasks requiring cognitive control also emerges from studies of bilingual speakers

140 (Abutalebi et al., 2013; Crinion et al., 2006; Friederici, 2006).

141 In sum, despite the wide variety of data showing an involvement of the striatum in language

142 processing, its specific role remains unclear. Ullman's proposal that the striatum is recruited

143 for the computation of grammatical rules is challenged by French HD data, showing rather

144 that only certain rules are affected by striatal atrophy, and by the large body of data showing

145 that the striatum is implicated in syntactic reanalysis and in the inhibition of competing 146 alternatives. Moreover, the dichotomist distinction between regular and irregular 147 morphological processes underlying Ullman's and Teichmann's proposals has been 148 questioned in the morphological literature by proposals of unified systems subsuming both 149 processes (Albright \& Hayes, 2003; Meunier \& Marslen-Wilson, 2004; Plunkett \& 150 Marchman, 1993; Rumelhart \& McClelland, 1986).

151 In this paper we propose that in order to identify the specific role of the striatum in language 152 processing it is necessary to consider an alternative to the proposals sketched above. More 153 precisely, it is necessary to consider that the striatum plays a more general role in linguistic 154 processing, akin to the role it plays in other cognitive domains, such as motor control, 155 attention, planning and decision-making (Alexander, DeLong, \& Strick, 1986; O'Doherty et 156 al., 2004). Results obtained from neurophysiology and neuroimaging suggest that this 157 structure filters cortical information to drive decision-making. Specifically, the striatum, and 158 particularly its dorsal parts (caudate nucleus and putamen), plays a key role in the 'action 159 selection' process (Kable \& Glimcher, 2009; Montague \& Berns, 2002; Rangel, Camerer, \& 160 Montague, 2008), by weighting the values assigned to the different options made available by 161 the prefrontal cortex (Hare, O'Doherty, Camerer, Schultz, \& Rangel, 2008; Padoa-Schioppa \& 162 Assad, 2008). 
163 In the domain of linguistic theory, this decomposition of the decision process into value

164 assignment and selection exhibits strong analogies with the processes assumed within the 165 framework of Optimality Theory (OT) (Prince \& Smolensky, 1993/2004). OT divides speech

166 production into two components. The evaluation component assigns wellformedness values to

167 possible spoken outputs given an underlying lexical input. The selection component selects

168 the optimal output on the basis of these values, like action selection. According to OT,

169 optimization is a general organizing principle underlying neural computation that can be

170 adapted to the theory of language. Whereas evaluation is dependent on language-specific

171 grammatical constraints, the operations of the selection component can be viewed as domain-

172 general, analogous to those involved in non-linguistic selection.

173 Here, we use OT as it provides us with the framework allowing us to assess whether the role

174 of the striatum in linguistic processing is analogous to its role outside of language.

175 Specifically, we hypothesize that the striatum is recruited for the selection of linguistic

176 alternatives, as for the selection of motor and other programs. To test this hypothesis we

177 studied patients with $\mathrm{HD}$, as this inherited neurodegenerative disease is a good model of

178 striatal lesion in its early stages (Douaud et al., 2006; Tabrizi et al., 2009; Vonsattel et al.,

179 1985). We independently validated our HD population as an appropriate model of patients

180 with striatal lesions, by comparing structural brain atrophy in these patients and a population

181 of healthy matched controls, by voxel-based morphometry (VBM).

182 The linguistic tasks previously used to reveal a role of the striatum in language processing do

183 not allow us to test our hypothesis. Tasks involving verbal conjugation in English and French

184 (e.g. Today he walks, yesterday he ... walked) (Teichmann et al., 2005; Teichmann et al.,

185 2008; Ullman et al., 1997) are not suited to test the selection process, as a limited number of

186 alternatives is available (i.e. English past tense: regular vs. irregular; French future tense:

187 regular, 'subregular', irregular). In addition to being very few in number, the alternatives 
within the set are not comparable with each other as some are regular alternations undergone

by a large set of lexical items and others are irregular, i.e. lexically very restricted. Tasks involving syntactic reanalysis or lexical inhibition are in principle better suited to test

191 linguistic selection processes. However, these tasks are not standardly modeled within OT and thus the relative contribution of the selection and the evaluation component is hard to assess.

193 We therefore set out to design a new task which could be modeled within OT, and in which 194 several comparable linguistic alternatives must be evaluated before selection. To assess whether the striatum holds a role in evaluation or in selection processes, we compared the performance of HD patients in this task with that of matched controls.

The grammar of French adjectives is the ideal paradigm to test linguistic selection. Unlike in English, where gender differences are not pronounced (compare small- FEMININE (FEM) and small- MASCULINE (MASC)), in French adjectives take on different forms depending on their gender (compare sportive-FEM and sportif-MASC 'athletic'). There are four common patterns

201 of alternation, Fig. 1A. These patterns are regular and instantiated by a large number of items in the French lexicon. This allows investigating the role of the striatum in evaluation and selection without the confounding distinction between regular, subregular and irregular 204 morphological processes. We designed an elicitation task, in which participants were given 205 the feminine form of a nonce adjective, and had to produce the corresponding masculine. The 206 feminine form was provided, as it is the underlying form of the adjective, i.e. the form from 207 which the masculine is derived.

208 The task requires grammatical knowledge about the four patterns and about their respective 209 wellformedness values in different linguistic contexts (evaluation). It also requires selecting 210 among these patterns, to produce the one with the highest value (selection).

211 If the evaluation process is impaired, patient should produce responses incompatible with the 212 underlying grammar of control participants. More specifically, patients' responses should be 
213 the outputs of a grammar in which constraints are ranked differently than those in the

214 grammar of controls, and thus evaluated differently. By contrast, if the selection process is 215 impaired, they should produce a response patterns should be very similar to those of the

216 controls - i.e. evaluated by the same language-specific constraint ranking, but with increased

217 randomness, with a more frequent selection of non-optimal alternatives.

218 To determine the specific function of the striatum in language, we instantiated computational 219 models of both evaluation and selection deficits using OT. We modeled the French adjective 220 system within Maximum Entropy Harmonic Grammar (MaxEntHG (Goldwater \& Johnson, 221 2003; Hayes \& Wilson, 2008)), a probabilistic variant of OT, and trained our model on the 222 data from our population of healthy controls. The computational model was then 'impaired' in 223 two ways to test our hypothesis. One impairment model simulated a grammatical deficit, 224 introducing noise in the constraint-based evaluation process (Goldrick \& Daland, 2009). The 225 other model simulated a selection deficit by increasing randomness in the selection process 226 (Palminteri et al., 2012), i.e. by selectively attenuating the signaling of the possible outcomes. 227 Computational modeling allows to refine our hypotheses and to directly test their predictions. 228 If patients' impairment is in the evaluation process, we expect the model simulating a 229 grammatical deficit to provide a better fit to the data produced by the patients. On the 230 contrary, if their impairment is in the selection process, we expect the model simulating a 231 selection deficit to provide a better fit to their data.

232 Additionally, we used VBM to assess whether the linguistic deficit in HD patients was 233 correlated with striatal atrophy. 
239 We included thirty carriers of the mutation responsible for HD (abnormal CAG expansion in 240 the Huntingtin gene) and thirty healthy controls with no family history of HD and no 241 neurological or psychiatric disorder. Patients were in the early phase of the disease, stage I of 242 the classification based on the Unified Huntington Disease Rating Scale (UHDRS 243 (Huntington Study Group, 1996)) total functional capacity (TFC) scale. Control participants 244 were matched to patients for age $\left(t_{55}=-0.01, P=0.99\right.$; Cohen's $d=-0.003$, C.I. [-0.52, 0.51]), $\operatorname{sex}\left(\chi^{2}(1)=0, P=1 ; \mathrm{OR}=0.87\right.$, C.I. $\left.[-0.7,0.88]\right)$, handedness $\left(\chi^{2}(1)=0.88, P=0.35 ; \mathrm{OR}=0.8\right.$,

C.I. $[-0.8,1.1])$ and educational level $\left(t_{57}=0.83, P=0.41\right.$; Cohen's $d=0.22$, C.I. $\left.[-0.3,0.73]\right)$.

Twenty-five HD patients were able to undergo a structural MRI scan within a three-month window around the linguistic task. Brain atrophy in patients was assessed by comparing their MRI scans with those of twenty-five additional healthy control subjects matched for age and sex. Information about handedness and educational level was not available for this group of control subjects. This group of subjects did not perform the behavioral task as it was only used to assess brain atrophy in our HD population.

253 All patients were evaluated with the UHDRS, which includes the Verbal Letter Fluency test 254 (Cardebat, Doyon, Puel, Goulet, \& Joanette, 1990), the Trial-Making Test A and B (TMT A and B) (Tombaugh, 2004), the Symbol Digit Modalities Test (SDMT (Wechsler, 1981)) and 256 the Stroop interference test (Golden, 1978). Patients also completed the Mattis Dementia 257 Rating Scale (MDRS (Mattis, 1976). Table 1 summarizes demographic and clinical data of 258 the participants included in the analyses.

259 The study was carried out in accordance with the Declaration of Helsinki. Participants were 260 recruited from an outpatient clinical biomarker program (NCT01412125) approved by the 261 ethics committee of Henri Mondor Hospital (Créteil, France). The committee approved all 
263 gave informed consent.

\begin{tabular}{|c|c|c|c|c|}
\hline & $\begin{array}{l}\text { Whole cohort of } \\
\text { HD patients }\end{array}$ & $\begin{array}{l}\text { Subgroup of HD } \\
\text { patients with } \\
\text { MRI }\end{array}$ & Controls & $\begin{array}{c}\text { Group of } \\
\text { Controls with } \\
\text { MRI }\end{array}$ \\
\hline $\mathrm{N}$ & 30 & 25 & 30 & 25 \\
\hline Sex & $15 \mathrm{~F} / 15 \mathrm{M}$ & $12 \mathrm{~F}, 13 \mathrm{M}$ & $16 \mathrm{~F} / 14 \mathrm{M}$ & $14 \mathrm{~F} / 11 \mathrm{M}$ \\
\hline Age (years) & $50.3 \pm 8.8$ & $50.8 \pm 8.6$ & $50.3 \pm 10.7$ & $50.4 \pm 9.7$ \\
\hline Years of education & $13.5 \pm 2.5$ & $13.3 \pm 2.5$ & $14 \pm 2.4$ & \\
\hline Handedness & $25 \mathrm{R} / 5 \mathrm{~L}$ & $22 \mathrm{R} / 3 \mathrm{~L}$ & $24 \mathrm{R} / 6 \mathrm{~L}$ & \\
\hline $\mathrm{N}$ of CAG repeats ${ }^{\mathrm{a}}$ & $44 \pm 2.1$ & $44 \pm 2.6$ & - & \\
\hline Disease burden score ${ }^{b}$ & $422.6 \pm 82.2$ & $395 \pm 94.6$ & . & \\
\hline \multirow[t]{2}{*}{$\mathrm{N}$ of years since disease onset } & $6.2 \pm 4.2$ & $6.7 \pm 4.4$ & - & \\
\hline & & & (normal values & \\
\hline UHDRS TFC ${ }^{c}$ & $11.6 \pm 0.7$ & $11.8 \pm 0.7$ & 13 & \\
\hline UHDRS motor $^{\mathrm{c}}$ & $22.9 \pm 13.1$ & $22.5 \pm 10.8$ & 0 & \\
\hline Mattis Dementia Rating Scale & $134.4 \pm 9.3$ & $134.8 \pm 9.8$ & $>136^{\mathrm{d}}$ & \\
\hline Letter fluency & $42.2 \pm 22.2$ & $46.4 \pm 23.1$ & $>45^{\mathrm{e}}$ & \\
\hline Stroop interference & $27.8 \pm 8.6$ & $28.6 \pm 8.6$ & $>35^{\mathrm{f}}$ & \\
\hline Symbol digit code & $31.1 \pm 10.1$ & $31.5 \pm 9.5$ & $>37^{g}$ & \\
\hline Trail-making test A (s) & $57.3 \pm 25.9$ & $55.1 \pm 21.9$ & $<31^{\mathrm{h}}$ & \\
\hline Trail-making test $\mathrm{B}(\mathrm{s})$ & $127.6 \pm 60.1$ & $119.3 \pm 56.9$ & $<64^{\mathrm{h}}$ & \\
\hline
\end{tabular}

$\mathrm{F}=$ female, $\mathrm{M}=$ male, $\mathrm{R}=$ right-handed, $\mathrm{L}=$ left-handed; ${ }^{\mathrm{a}}$ Number of $\mathrm{CAG}$ repeats in the $\mathrm{Htt}$ gene; ${ }^{\mathrm{b}}$ Diseaseburden score $=$ age $\times($ CAG length -35.5$)$, Penney et al. (1997). ${ }^{c}$ UHDRS $=$ United Huntington Disease Rating Scale, TFC = total functional capacity score, Huntington Study Group (1996); *Normal values were obtained from: ${ }^{\mathrm{d}}$ Mattis (1976); ${ }^{\mathrm{e}}$ Cardebat et al. (1990) - values for 2 min for the 3 letters P, R and V; ${ }^{\mathrm{f}}$ Golden (1978), color/words; ${ }^{\mathrm{g}} \mathrm{Wechsler}(1981) ;{ }^{\mathrm{h}}$ Tombaugh (2004)

Table 1 Demographic and genetic information for HD patients, demographic data for controls, and results from the neurological and neuropsychological assessments of HD patients

\subsection{Behavioral task}

Stimuli and procedure. Stimuli belonged to the four common alternation patterns present in the French lexicon (type frequency >100 per million (Bybee, 1995; New, Pallier, Ferrand, \& Matos, 2001)) (alternatives 1-4 in Fig. 1A). The token frequency of the different patterns is 3.74 for No change, 3.82 for Deletion, 4.44 for Nasalization and 0.82 for Use -if. For each 
282 adjectival endings. For instance, Nasalization was instantiated by the feminine endings '-ine',

283 '-aine', '-une', '-onne'. This was done to include the different lexical instantiations of each

284 alternation pattern and ensure to variability in the experimental material. Test items were

285 nonce disyllabic adjectives to optimize the grammatical evaluation and selection components

286 of the task, minimizing lexical effects. For each feminine ending type, fifteen nonce adjectives

287 were created by adding, subtracting, or substituting two phonemes from an existing French

288 adjective, for a total of 165 stimuli. The stimuli were matched for number of phonemes $(F>1)$

289 and consisted of legal phoneme strings that differed in at least two phonemes from any

290 existing French word.

Figure 1 Description and model of the linguistic task. Model of the linguistic task with two

distinct components (a). Given a feminine input, harmony values $(h)$ are assigned to possible masculine alternatives in the Evaluation component. Other refers to the set of alternatives with low harmony values that could be generated by the grammar but would not be selected by the Selection component. In the Selection component, a masculine output is selected on the basis of these values. Derivation of a masculine adjective from its feminine counterpart, with an example from the French lexicon (gloutonne, 'glutton') (b). Example of a behavioral trial with the nonce adjective deronne (c). Text outside the brackets corresponds to the orthographic form; text in square brackets corresponds to the actual pronunciation of the form, 303 transcribed using the International Phonetic Alphabet (IPA). The IPA symbols $\partial$, R and in 304 [dəRən] correspond respectively to the sound of the first vowel in again in American English, to the French sound for $r$ and to the sound of the first vowel in all in American English. The diacritic $\sim($ as in [dəR̃̃]]) indicates a nasal vowel. 
Participants were presented with a spoken sentence containing the relevant nonce adjective in

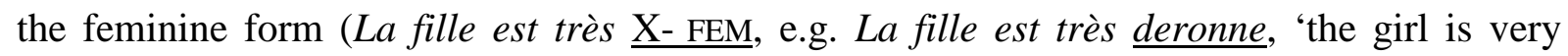
deronne-FEM'), and were asked to provide the sentence containing the corresponding masculine (Le garçon est très $\underline{\mathrm{X}-\mathrm{MASC}}$, e.g. Le garçon est très $\underline{\text { deron, }}$, the boy is very deronMASC'). Feminine forms were randomized for each participant. We familiarized participants to the task by training them with feedback. Practice items included real feminine adjectives and nonce adjectives.

316 Responses were categorized into four types (No change, Deletion, Nasalization, Use -if).

317 Responses that matched the expected form were coded as correct; all other responses were 318 coded as incorrect. For one of the eleven feminine ending types, "-te", two masculine 319 responses were coded as correct, i.e. Deletion and No change, since both alternation patterns 320 are attested in the French lexicon for these feminine forms (compare e.g. petite-FEM [pətit] petit-MASC [pəti] 'small', and tacite-FEM [tasit] - tacite-MASC [tasit]), although the first one 322 is much more frequent than the second one. As an example of how responses were coded, if 323 the speaker heard deronne, the correct response, deron, would be considered to correspond to 324 Nasalization, whereas the incorrect responses deronne, dero and derif would be coded as No change, Deletion, and Use -if errors, respectively; all other incorrect responses were coded as Aberrant (e.g. derer), (Fig. 1C).

328 Data analysis. R package lme4 (Bates D., 2015) was used for statistical analyses. Linear 329 mixed-effects models were used to analyze participants' responses. By-subject random 330 intercepts and slopes were included. We evaluated the relationship between linguistic 331 performance and the results of clinical assessment tests, and sociodemographic data, with 332 Pearson's product-moment correlation analyses. 


\subsection{Brain damage delineation}

MRI data acquisition. Brain MRI scans were obtained for twenty-five of our thirty HD patients and for twenty-five healthy controls matched for age and sex (t-test: $t_{48}=0.22, P=0.83$ and chi-square test: $\chi^{2}(1)=0.32, P=0.57$, respectively, Table 1$)$, to delineate gray matter (GM)

atrophy in our HD population. All scans were acquired at Henri Mondor Hospital, on a

Siemens Symphony 1.5T MRI scanner with a 12-channel head coil. A T1-weighted acquisition (MP-RAGE, TE/TR=3.72/2400 ms, $\mathrm{TI}=1000 \mathrm{~ms}$, flip angle $=8^{\circ}$, acquisition matrix $=256 * 256, \mathrm{FOV}=256 \times 256 \mathrm{~mm}$, voxel size $=1 \times 1 \times 1 \mathrm{~mm}^{3}$, sagittal sections: 160 ) was used to perform VBM analyses.

MRI data analysis. VBM data preprocessing and analysis were performed with VBM8 (http://dbm.neuro.uni-jena.de/vbm/), an SPM8 toolbox (http://www.fil.ion.ucl.ac.uk/spm) running on Matlab. Structural images were corrected for intensity bias, tissue-classified and registered, using linear and non-linear transformations (DARTEL), within a unified model (Ashburner \& Friston, 2005). GM segments for each subject were modulated using non-linear components of the normalization only, thereby preserving actual tissue values locally, to take

351 individual brain size into account globally. Modulated, normalized GM segments were 352 smoothed with a 6-mm FWHM Gaussian kernel.

353 A full factorial design model assessed group differences in GM volume between control and 354 HD patients with group as main factor and age as covariate. An average GM mask was 355 created from the normalized GM segments of the twenty-five healthy controls, thresholded at 356 a value of 0.20 (voxels with $>20 \%$ GM fraction values). This mask was used to restrict 357 statistical comparisons to the GM. Results were corrected for multiple comparisons using 
358 family-wise error (FWE-corrected, $P<0.05$ ). Anatomical labeling of significant clusters was

359 achieved using the AAL atlas implemented in MRIcro software

360 (http://cnl.web.arizona.edu/mricro.htm). A binary mask was created by pooling the significant

361 clusters in this group analysis, representing the areas of GM atrophy in HD patients (Fig. 3A

362 and B). This mask was used for subsequent correlation analyses with behavioral data.

\subsection{Correlations between behavioral data and GM atrophy}

Correlation analyses within the GM mask. A multiple regression analysis explored the correlation between linguistic performance and whole brain GM volumes in HD patients, with education level as covariate. Statistical outcomes were observed with corrected $p$-values inferior to 0.05 using Family-Wise Error (FWE) and a minimum of 25 voxels per cluster.

Correlation analyses within the mask of GM atrophy in HD patients. A multiple regression analysis explored the correlation between linguistic performance and GM volumes in HD patients, restricted to regions showing atrophy in HD patients in comparison with controls, with education level as covariate. Statistical outcomes were observed with corrected $p$-values inferior to 0.05 using Family-Wise Error (FWE) and a minimum of 25 voxels per cluster.

The same analyses were conducted to investigate the correlation between GM volume and 377 clinical scores (Stroop interference, SDMT, UHDRS motor score and disease burden score 378 (Penney, Vonsattel, MacDonald, Gusella, \& Myers, 1997)).

Correlation analyses with mean probability of GM in five striatal ROIs. The striatum was 381 manually segmented into five bilateral a priori anatomical masks (caudate body, caudate 382 head, anterior putamen, posterior putamen and ventral striatum, including the nucleus 
accumbens). ROIs were defined for each hemisphere with MRIcro applied to the singlesubject T1 template of SPM8 software as follows: The ventral striatum comprises all striatal voxels in which the demarcation between caudate and putamen is not visible; the anterior and posterior putamen comprise the putaminal voxels with ' $y$ ' coordinates higher and lower than zero, respectively; the caudate head and body comprise the caudate voxels with 'y' coordinates higher and lower than zero, respectively (Douaud et al., 2006). The mean probabilities of GM found in these ROIs were extracted. Multiple linear regression analyses assessed the association of performance in the linguistic task with mean probability of GM in each bilateral striatal ROI, for all HD patients. Education level was used as covariate. Results were Bonferroni-corrected.

\subsection{Computational modeling}

Baseline model. The modeling process began with a phonological analysis of the French adjective system in MaxEntHG. In MaxEntHG, speech production consists of an evaluation stage and a selection stage. The evaluation stage begins with an input lexical representation (here, the feminine form of the adjective) and a small number of possible output pronunciations (potential masculine forms). Each input-output mapping is assessed by constraints. There are two types of constraints: faithfulness constraints, according to which the input should be similar to output, and markedness constraints, according to which the output should be simple to produce and to perceive. Constraints are associated with weights and the harmony of a mapping is the weighted sum of its constraint violations. Thus, the evaluation stage involves the assignment of harmony values to every possible mapping:

$$
\operatorname{Harmony}\left(i, o_{\mathrm{j}}\right)=\stackrel{\circ}{\mathrm{k}}_{w_{\mathrm{k}}} \cdot \mathrm{C}_{\mathrm{k}}\left(i, o_{\mathrm{j}}\right), \quad \text { where }
$$



masculine form (the output)

In the selection stage, a particular output is selected with a probability proportional to its

414 harmony:

$$
\operatorname{Pr}\left(o_{\mathrm{j}} \mid i\right)=\exp \left(\operatorname{Harmony}\left(i, o_{\mathrm{j}}\right)\right) / \mathrm{Z}_{i}, \quad \text { where }
$$

\section{8}

Thus, for a given constraint set and a given set of weights, Equation [2] predicts a probability distribution over all outputs for each input.

The analysis involved choosing constraints that could yield the French adjectival system. We used eight standard phonological constraints. The optimal weights for a given set of data were determined by maximizing the likelihood of the data, according to Equation [2] (assuming

424 independence). The optimum was identified by gradient ascent, using the BFGS_B method in 425 NumPy (Byrd, Lu, \& Nocedal, 1995). Constraint weights of the baseline model were 426 determined from the aggregate production data of the control population. The baseline model thus represents the behavior of a typical speaker, as estimated from the outputs produced by control participants.

Deficit models. It is convenient to write the evaluation and the selection steps in vector form,

431 i.e. letting $\mathbf{w}_{\text {base }}=\left[w_{1}, w_{2}, \ldots\right]$ and $\mathbf{C}\left(i, o_{\mathrm{j}}\right)=\left[\mathrm{C}_{1}\left(i, o_{\mathrm{j}}\right), \mathrm{C}_{2}\left(i, o_{\mathrm{j}}\right), \ldots\right]$, where $\mathbf{w}_{\text {base }}$ represents the weights of the baseline model, as estimated above: 
Evaluation

$$
\operatorname{Harmony}\left(i, o_{\mathrm{j}}\right)=\mathbf{w}_{\mathrm{base}} \cdot \mathbf{C}\left(i, o_{\mathrm{j}}\right)
$$

$$
\operatorname{Pr}\left(o_{\mathrm{j}} \mid i\right)=\exp \left(\operatorname{Harmony}\left(i, o_{\mathrm{j}}\right)\right) / \mathrm{Z}_{i}
$$

We derived two classes of deficit models from these equations. In the evaluation deficit model, a speaker $s$ is assumed to differ from the baseline model by the addition of a constant noise vector $\eta_{s}$ drawn from a zero-centered Gaussian distribution with standard deviation $\eta$.

In the selection deficit model, a speaker $s$ is assumed to differ from the baseline model in that the harmony is multiplied by a constant weakening factor $\lambda_{s}$, drawn from a uniform distribution over the interval $[a, b], 0 \leq a \leq b \leq 1$.

$$
\operatorname{Pr}_{\mathrm{s}}\left(o_{\mathrm{j}} \mid i\right)=\exp \left(\lambda_{s} \cdot \operatorname{Harmony}\left(i, o_{\mathrm{j}}\right)\right) / Z_{i}
$$

Thus, the evaluation deficit model has the 'noise level' $\eta$ as a free parameter, and the selection deficit model has the 'weakening level' $\lambda$ as a free parameter.

Simulation. Monte-Carlo method was used to derive predictions from a stochastic theory by explicitly simulating the stochastic process repeatedly. A run $R$ proceeded as follows. First, thirty copies of the control grammar were produced (matched to the number of HD patients). Each copy was then perturbed according to the selection deficit or evaluation deficit above. Thus, every $s$ models a typical speaker of French afflicted by either a selection deficit or an evaluation deficit. Within a run, every $s$ has the same deficit. All thirty s's perform the same task as HD patients, generating masculine adjective forms from the feminine forms, according to the distributions generated by Eq.'s [1-4]. Outputs from each speaker $s$ within the run are aggregated, yielding a sample from the predicted distribution (for the selection or evaluation 
462 distribution, depending on the run), with $\operatorname{Fr}_{\mathrm{R}}\left(o_{\mathrm{j}} \mid i\right)$ representing the total number of times the

463 masculine form $o_{\mathrm{j}}$ was produced for for feminine form $i$. The $\log$ probability of a run $R$ is

464 determined by Eq. [5]:

465

466

$$
\mathrm{L}(\mathrm{R})=\Sigma_{(\mathrm{i}, \mathrm{j})} \operatorname{Fr}_{\mathrm{R}}\left(o_{\mathrm{j}} \mid i\right) \ln \operatorname{Pr}_{H D}\left(o_{\mathrm{j}} \mid i\right)
$$

467

468 Conditional probabilities $\operatorname{Pr}_{H D}\left(o_{\mathrm{j}} \mid i\right)$ in Eq. [5] are estimated from the HD patient data using 469 add-one smoothing, e.g. $\operatorname{Pr}_{H D}\left(o_{\mathrm{j}} \mid i\right)=\left(1+\mathrm{Fr}_{H D}\left(i, o_{\mathrm{j}}\right)\right) /\left(\Sigma_{\mathrm{k}} 1+\mathrm{Fr}_{H D}\left(i, o_{\mathrm{k}}\right)\right)$. The log probability of 470 a run is a relative measure of how much the sample output distribution (selection or 471 evaluation deficit) resembles the actual output distribution from HD patients. One thousand 472 runs were conducted with each deficit model.

473 The deficit models were assessed by determining which one assigned higher probability to the 474 data. On individual runs, either the evaluation or the selection deficit model might assign 475 higher data likelihood, indicating that the ability to account for the data was not baked into 476 either. Nonetheless, the selection deficit model provided a better fit to the data on an average 477 run, indicating it is a closer match to HD patients' speech production process.

\section{RESULTS}

\subsection{Behavioral results}

HD patients performed worse than controls $\left(76.4 \%\right.$ and $89.9 \%$ accuracy, respectively $\left[F_{1}\right.$, $\left.\left.{ }_{58}=4.77, P<0.05\right]\right)$. Table 2 illustrates the distribution of responses for each alternation included in the experiment. 


\begin{tabular}{|c|c|c|c|c|c|c|}
\hline & & \multicolumn{5}{|c|}{ Response type (\%) } \\
\hline \multirow{6}{*}{ 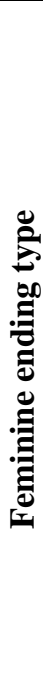 } & & No change & Deletion & Nasalization & Use -if & Aberrant \\
\hline & $\begin{array}{l}\text {-le [-l] } \\
\text { nurfale } \\
\text { [nyRfal] }\end{array}$ & $\begin{array}{c}90.18 / 68.89 \\
\text { nurfale } \\
\text { [nyrfal] }\end{array}$ & $\begin{array}{c}2.13 / 6.56 \\
\quad \text { nurfa } \\
\text { [nykfa] }\end{array}$ & $\begin{array}{c}2.45 / 8.44 \\
\text { nurfan } \\
\text { [nyRfã] }\end{array}$ & $\begin{array}{c}0.00 / 0.00 \\
\text { nurfif } \\
\text { [nyRfif] }\end{array}$ & $\begin{array}{c}5.24 / 16.11 \\
\text { nurfo } \\
\text { [nyrfo] }\end{array}$ \\
\hline & $\begin{array}{l}\text {-te [-t] } \\
\text { spamite } \\
\text { [spamit] }\end{array}$ & $\begin{array}{c}16.04 / 21.22 \\
\text { spamite } \\
\text { [spamit] }\end{array}$ & $\begin{array}{c}81.07 / 66.11 \\
\text { spami } \\
\text { [spami] }\end{array}$ & $\begin{array}{l}1.22 / 8.45 \\
\text { spamin } \\
\text { [spamẽ] }\end{array}$ & $\begin{array}{l}1.33 / 2.00 \\
\text { spamif } \\
\text { [spamif] }\end{array}$ & $\begin{array}{c}0.34 / 2.22 \\
\text { spamol } \\
\text { [spamol] }\end{array}$ \\
\hline & $\begin{array}{l}\text {-se }[\mathbf{z}] \\
\text { stopise } \\
\text { [stopiz] }\end{array}$ & $\begin{array}{l}1.22 / 5.00 \\
\text { stopise } \\
\text { [stopiz] }\end{array}$ & $\begin{array}{c}88.18 / 65.28 \\
\text { stopi } \\
\text { [stopi] }\end{array}$ & $\begin{array}{c}2.34 / 13.46 \\
\text { stopin } \\
\text { [stop } \tilde{\varepsilon}]\end{array}$ & $\begin{array}{c}4.56 / 6.22 \\
\text { stopif } \\
\text { [stopif] }\end{array}$ & $\begin{array}{c}3.70 / 10.04 \\
\text { stoper } \\
\text { [stoper] }\end{array}$ \\
\hline & $\begin{array}{l}\text {-ne [n] } \\
\text { polune } \\
\text { [polyn] }\end{array}$ & $\begin{array}{l}2.50 / 8.40 \\
\text { polune } \\
\text { [polyn] }\end{array}$ & $\begin{array}{c}0.50 / 4.12 \\
\text { polu } \\
\text { [poly] }\end{array}$ & $\begin{array}{c}96.61 / 85.25 \\
\text { polun } \\
\text { [polõ] }\end{array}$ & $\begin{array}{c}0.22 / 0.50 \\
\text { polif } \\
\text { [poloif] }\end{array}$ & $\begin{array}{c}0.17 / 1.73 \\
\text { polsane } \\
\text { [polsan] }\end{array}$ \\
\hline & $\begin{array}{l}\text {-ive [iv] } \\
\text { merive } \\
\text { [məRiv] }\end{array}$ & $\begin{array}{l}2.44 / 7.11 \\
\text { merive } \\
\text { [moriv] }\end{array}$ & $\begin{array}{c}1.56 / 12.00 \\
\text { meri } \\
{[\mathrm{m} ə \mathrm{Ri}]}\end{array}$ & $\begin{array}{c}2.89 / 17.33 \\
\text { merin } \\
{[\mathrm{məR} \tilde{\varepsilon}]}\end{array}$ & $\begin{array}{c}93.11 / 62.00 \\
\text { merif } \\
\text { [məRif] }\end{array}$ & $\begin{array}{c}0.00 / 1.56 \\
\text { merta } \\
{[\text { məRta }]}\end{array}$ \\
\hline
\end{tabular}

489 Table 2 Distribution of participants' responses for each alternation. Lines correspond to the different feminine ending types. Columns correspond to the alternation pattern used by

491 participants to produce the masculine form. Shaded cells correspond to responses coded as

492 'correct', non-shaded cells correspond to cells coded as errors (for the ending type "-te" see

493 the stimuli description in the Material and Methods section). Numbers in each line correspond

494 to percentages out of the total number of responses, across participants (Controls, left and HD patients, right). Feminine and masculine forms are provided according to the French orthography (in italics) and according to the International Phonetic Alphabet (IPA) (in square brackets), which correspond to the actual pronunciation of the form.

499 As Figure 2 shows, HD patients followed the same response pattern as Controls, but more noisily. We found an interaction between subject group and error type [ $\left.F_{4,232}=3.64, P<0.01\right]$,

501 due to a combination of two factors, as shown by two post-hoc analyses. First, HD patients 502 made errors concerning the most frequent alternation patterns in the French lexicon more 503 frequently than controls $\left[F_{1,177}=9.27, P<0.01\right]$. For instance, HD patients were more likely to 504 produce a Nasalization error (e.g. nurfale - nurfan), where the lexical token frequency is 4.4 
per million words (New et al., 2001), than a Use-if error (e.g. nurfale - nurfif), where the Use-

506 if alternation is less frequent in the French lexicon (token frequency $=0.83$ per million words).

507 Second, HD patients perseverated more than controls. A perseverative error was defined as an

508 error due to the erroneous application of the same alternation pattern as the one given in the

509 previous two trials (HD patients: mean=5.3, controls: mean=3.8, $P<0.05$ ). These

510 perseverations were not due to the fact that randomization yielded a greater number of

511 consecutive trials in HD patients than in controls. In fact the difference between then two

512 groups was restricted to perseveration errors but there was no difference between groups for

513 correct consecutive responses of the same type (HD patients: mean=4.13, controls:

514 mean=4.03, $P=0.7)$.

Figure 2 Behavioral responses. Response types provided by the subjects for the 5 feminine ending types (-le [1], -te [t], -se [z], -ne [n], -ive [iv]); Controls (a) and HD patients (b). Axes correspond to the types of response provided by the subjects; circles represent percentages.

522 Performance in the linguistic task was correlated with level of education in HD patients and 523 controls, and with the CAG repeat length and the UHDRS motor score in HD patients.

524 Linguistic performance of HD patients was also correlated with the MDRS memory and 525 attention scores, with the Stroop interference score, the SDMT, Verbal Letter Fluency and 526 TMT A and B (Table 3).

Linguistic performance 


\begin{tabular}{|c|c|c|c|}
\hline \multicolumn{4}{|l|}{ Demographic data } \\
\hline Age & n.s. & n.s. & n.s. \\
\hline Years of education & $0.48 * * *(57)$ & $0.36 * *(52)$ & $0.48 * * *(57)$ \\
\hline Sex & n.s. & n.s. & n.s. \\
\hline \multicolumn{4}{|l|}{ General assessment } \\
\hline UHDRS motor ${ }^{\mathrm{a}}$ & $-0.44 *(27)$ & $-0.64 * * *(23)$ & - \\
\hline UHDRS TFC ${ }^{\mathrm{a}}$ & n.s. (28) & n.s. (23) & - \\
\hline $\mathrm{N}$ of CAG repeats ${ }^{\mathrm{b}}$ & $-0.55 * *(26)$ & $-0.46 *(19)$ & - \\
\hline Disease burden score ${ }^{\mathrm{c}}$ & $-0.46 *(26)$ & $-0.46 *(19)$ & - \\
\hline $\mathrm{N}$ of years since disease onset & n.s. (24) & n.s. (18) & \\
\hline \multicolumn{4}{|l|}{ Cognitive assessment } \\
\hline MDRS memory ${ }^{\mathrm{d}}$ & $0.79 * * *(27)$ & $0.83 * * *(20)$ & - \\
\hline MDRS attention ${ }^{\mathrm{d}}$ & $0.66 * * *(27)$ & $0.66 * *(20)$ & _- \\
\hline Letter fluency ${ }^{\mathrm{e}}$ & $0.62 * * *(27)$ & $0.67 * * *(20)$ & - \\
\hline Stroop interference ${ }^{\mathrm{f}}$ & $0.69 * * *(27)$ & $0.63 * *(22)$ & - \\
\hline Symbol digit code $\mathrm{f}^{\mathrm{f}}$ & $0.65 * * *(27)$ & $0.72 * * *(23)$ & - \\
\hline Trail-making test A (s) & $-0.38 *(27)$ & $-0.47 *(20)$ & _- \\
\hline Trail-making test B (s) & $-0.62 * * *(27)$ & $-0.59 * *(20)$ & - \\
\hline
\end{tabular}

Table 3 Results of the partial correlation analyses between linguistic performance and

531 demographic data, clinical and cognitive assessment and genetic measurements, and the

532 results of a Welch two-sample $t$-test for sex (degrees of freedom in parentheses). n.s. $=$ non-

533 significant $(\mathrm{P}>0.05) ; * \mathrm{P}<0.05 ; * * \mathrm{P}<0.01 ; * * * \mathrm{P}<0.001 .{ }^{\mathrm{a}} \mathrm{UHDRS}=$ United Huntington

534 Disease Rating Scale, TFC = total functional capacity score, Huntington Study Group (1996);

$535{ }^{\mathrm{b}}$ Number of CAG repeats in the $\mathrm{Htt}$ gene; ${ }^{\mathrm{c}}$ Disease-burden score=age $\times(\mathrm{CAG}$ length-35.5),

536 Penney et al. (1997); ${ }^{\mathrm{d}}$ Mattis Dementia Rating Scale, Mattis (1976); ${ }^{\mathrm{e}}$ Cardebat et al. (1990) -

537 values for 2 min for the 3 letters P, R and V; ${ }^{\mathrm{f}}$ Golden (1978), color/words; ${ }^{\mathrm{g}} \mathrm{Wechsler}(1981)$;

$538{ }^{\mathrm{h}}$ Tombaugh (2004)

\subsection{Brain damage delineation}

542 The between-group VBM analysis revealed reduced GM volume in HD patients as compared

543 to healthy controls, in the basal ganglia (caudate nucleus and putamen, bilaterally, and right 544 globus pallidus) and the frontal cortex (precentral and orbital) (Fig. 3A, Table 4). No 
545 significant increase in regional GM volume was found in HD patients relative to controls. A

546 binary GM mask including significant clusters for this group effect (Controls vs. HD patients,

547 CON $>$ HD) was built (Fig. 3B) for subsequent analyses of correlations with behavioral data.

Figure 3 Neural correlates of linguistic performance in Huntington's Disease using

VBM. Regions displaying areas of reduced GM volume (atrophy) in Huntington's Disease patients compared to controls (FWE, $P<0.05$, corrected $t>5.35$, extent cluster threshold set at 50 contiguous voxels), overlaid onto a glass brain (a). Binary GM mask of significant clusters

555 from the group comparison (controls vs. Huntington's Disease patients), overlaid onto the 556 average template of GM of the twenty-five Huntington's Disease patients, built with the 557 TOM8 toolbox (http://dbm.neuro.uni-jena/software/tom/) (b). Correlation between GM 558 volume in the GM atrophy mask and linguistic performance in the twenty-five HD patients 559 (FWE-corrected, $P<0.05$ ), overlaid onto the average template of GM of the twenty-five HD 560 patients; two clusters are identified, the right caudate nucleus ( $x y z$ coordinates of maxima in 561 MNI space: $1124-2$, cluster size: 40 voxels, $T=5.03$ ) and the left caudate nucleus ( $x$ y $z$ 562 coordinates: $-1211-3$, cluster size: 35 voxels, $\mathrm{T}=4.44)(\mathrm{c})$. Description of the five striatal 563 ROIs overlaid onto the average template of GM (d). Results of the correlation analysis 564 between the probability of GM in each ROI and linguistic performance, with the correlation 565 coefficient $\beta$ and $*$ for $P<0.05$ (e).

\begin{tabular}{lllllll}
\hline Anatomical region & Side & $\begin{array}{l}\text { Cluster size } \\
\text { N voxels }\end{array}$ & $\mathrm{T}$ & \multicolumn{2}{c}{$\begin{array}{c}\text { MNI coordinates } \\
\text { (x y z, mm) }\end{array}$} \\
\hline $\begin{array}{l}\text { Basal ganglia } \\
\text { Caudate nucleus (head) }\end{array}$ & $\mathrm{L}$ & $2782^{*}$ & 10.64 & -12 & 9 & -3 \\
$\begin{array}{l}\text { Putamen } \\
\text { Caudate nucleus (body) }\end{array}$ & & & 10.25 & -21 & 5 & 7 \\
Globus Pallidus & $\mathrm{R}$ & $3064^{*}$ & 9.89 & -9 & 0 & 13 \\
Putamen & & & 10.93 & 14 & 9 & -6 \\
\end{tabular}




\begin{tabular}{|c|c|c|c|c|c|c|}
\hline Caudate nucleus (body) & & & 9.78 & 12 & 5 & 16 \\
\hline \multicolumn{7}{|l|}{ Frontal cortex } \\
\hline Precentral gyrus & $\mathrm{L}$ & 201 & 8.25 & -44 & 8 & 30 \\
\hline Medial Orbital & & 52 & 6.50 & -8 & 51 & -5 \\
\hline Superior Orbital & & $99 *$ & 6.09 & -23 & 30 & -17 \\
\hline Inferior Orbital & & & 5.89 & -29 & 36 & -15 \\
\hline Inferior Orbital & $\mathrm{R}$ & 53 & 6.76 & 36 & 38 & -12 \\
\hline Medial Orbital & & $112 *$ & 6.44 & 3 & 36 & -12 \\
\hline Olfactory & & & 5.78 & 2 & 24 & -12 \\
\hline
\end{tabular}

Table 4 Results of voxel-based analysis for assessing regional GM differences between controls and Huntington's Disease patients, with age as a covariate (FWE-corrected, $p<$ 0.05). * indicates contiguous clusters. Only clusters larger than 50 contiguous voxels are reported.

\subsection{Correlations between linguistic performance and GM atrophy}

Multiple regression analyses explored the correlation between accuracy in the linguistic task and GM volume in the twenty-five HD patients who underwent structural MRI. Like the whole cohort, these patients responded less accurately than their matched controls $(79.8 \%$ and $89.9 \%$ correct responses, respectively $\left.\left[F_{1,53}=4.11, P<0.05\right]\right)$. See Table 3 for correlation analyses with demographic and neuropsychological data.

Correlation analyses within the GM mask. In the correlation analysis on the whole brain, did no reveal any correlation between GM regions, cortically and subcortically, and accuracy in the linguistic task.

Correlation analyses within the mask of GM atrophy in HD patients. The analysis was restricted to the GM mask obtained from the between-group comparison $(\mathrm{CON}>\mathrm{HD}, 3 \mathrm{~A}$ and 3B). A positive correlation was found between accuracy in the linguistic task and GM volume 
in the bilateral caudate nucleus of HD patients (FWE-corrected, $P<0.05$ ) (Fig. 3C), but not in

590 the frontal areas. Scores of executive function tests (SDMT and Stroop) did not correlate with

591 GM volume within the striatum. The SDMT correlated with GM volume in the inferior

592 orbitofrontal gyrus, bilaterally (FWE-corrected, $P<0.05$ ). Conversely, the UHDRS motor

593 score correlated bilaterally with GM volume in both the putamen and the caudate nuclei, and

594 the disease burden score was negatively correlated with GM volume in the right caudate

595 nucleus (FWE-corrected, $P<0.05$ ).

596

597 Correlation analyses with mean probability of GM in five striatal ROIs. Among the five 598 striatal regions of interest (ROIs) (Fig. 3D), accuracy in the linguistic task only correlated 599 with the mean probability of GM in the caudate heads and the caudate bodies $(\beta=0.54, P<0.05$ 600 and $\beta=0.52, P<0.04$, respectively, Bonferroni-corrected, Fig. 3E). No neuropsychological or 601 clinical score correlated with GM in the five ROIs, apart from the UHDRS motor score, 602 which negatively correlated with caudate head $(\beta=-0.51, P<0.05)$, anterior putamen $(\beta=-0.59$, $603 P<0.01)$ and ventral striatum $(\beta=-0.66, P<0.01)$.

604

605

\subsection{Computational results}

606

607 There was a linear relationship between the log frequency of HD patients' responses and the

608 responses of controls for the same feminine-masculine adjective pair $\left(\mathrm{R}^{2}=0.87\right)$. This suggests 609 that a log-linear model is suited to model the alternation, since in log-linear models the 610 probability of generating an item is proportional to the exponential of some score function. As

611 the correlation is quite strong in the log domain, it suggests that the score function for HD 612 patients is 'close' to the score function for controls, i.e. HD can be understood as applying 613 some simple transform to the score function. Since in the field of morpho-phonology, a log- 
614 linear model OT-based model called MaxEntHG already exists and many properties of the

615 scoring function are understood, it was used to model the alternation. MaxEntHG allows one

616 to separate the process of attributing values to masculine output options from the process of

617 selecting amongst masculine outputs, by capturing them with different parameters.

618 We first determined the constraint weights of the baseline model by maximizing the

619 likelihood of the aggregated production data for the control population. We then derived two 620 classes of deficit models from the baseline model. In the evaluation deficit model, a speaker $s$ 621 is assumed to differ from the baseline model by the addition of a constant noise vector $\eta_{s}$. In

622 the selection deficit model, a speaker $s$ is assumed to differ from the baseline model in that the 623 harmony is multiplied by a constant weakening factor $\lambda_{s}$. The 'best' values for $\eta$ and $\lambda$ were 624 determined empirically by trying a variety of values. The values which assigned the greatest 625 likelihood on average to the HD patient data were $\eta=0.9$ and $\lambda=0.6$.

626 Monte-Carlo method was used to derive predictions from a stochastic theory by explicitly 627 simulating the stochastic process repeatedly. One thousand runs were conducted with each 628 deficit model. Outputs from each speaker $s$ within the run were aggregated and the $\log$ 629 probability of each run was determined. Results show that the selection deficit model accounts 630 significantly better for the data (mean log likelihood -3867.81 , median -3864.53; 631 heteroscedastic $t$-test $t_{1005}=-22.27, P<0.001$ ) than the evaluation deficit model (mean $\log$ 632 likelihood -3909.08, median -3902.66).

\section{DisCUSSION}

636 We investigated the mechanisms underlying language impairment in patients with striatal 637 lesions, using $\mathrm{HD}$ as a model. Moving beyond phenomenological descriptions of the 638 impairment, we used behavioral, imaging and modeling methods to investigate the 
computational mechanisms of language processing. This approach allowed us to test a new

640 hypothesis of the role of the striatum in language and, thus, to propose a new theory of the 641 source of language impairment in striatal lesions.

642 Patients with early HD performed worse than their matched controls in the linguistic task.

643 Their accuracy (76.4\%) was comparable to the one reported by previous studies testing 644 morphological abilities in these patients (e.g. ca. 75\% in (Teichmann, Dupoux, Kouider, \& 645 Bachoud-Levi, 2006)). This poor performance was associated with reduced striatal volume, as 646 revealed by the VBM analysis. Patients produced errors falling in the four standard patterns 647 for French adjectives. This response pattern was qualitatively similar to the one of control 648 participants. Quantitatively, however, it was different, in that the number of selected non649 optimal alternatives was higher. Our behavioral result thus indicates that the core grammatical 650 component responsible for generating the possible masculine outputs is spared in HD patients. 651 The observed similarity between the two response patterns is problematic for theories 652 assigning the striatum a role in the computation of linguistic rules (Nemeth et al., 2012;

653 Teichmann et al., 2006; Teichmann et al., 2005; Teichmann et al., 2008; Ullman, 2006; 654 Ullman et al., 1997). If HD patients had a core grammatical deficit, we would expect them to 655 produce responses that are incompatible with the grammar of French (i.e. responses of the 656 type Aberrant), contrary to fact.

657 Our computational analysis using MaxEntHG sheds light on the specific nature of the deficit 658 in HD. Provided that the chosen computational model and its parameters are accurate 659 abstractions of language production mechanisms in humans, these modeling results support 660 the hypothesis that the language deficits observed in patients are caused by a selection deficit 661 rather than by an impairment of underlying grammatical knowledge. We showed that the 662 noisier distribution of responses following striatal damage can be captured specifically, by 663 introducing randomness in the selection process (simulated by the selection deficit model). By 
contrast, introducing noise in the harmony calculation (simulated by the evaluation deficit model) yielded a poor fit to the patients' data.

Our modeling results are consistent with the notion that, even in language processing, the striatum is responsible for processing the outcomes of the evaluation component, to favor the more frequent selection of the best option, as suggested in studies of reinforcement and 669 punishment learning (O'Doherty et al., 2004; Palminteri et al., 2012).

670 OT allows us to disentangle two distinct processes occurring during language processing: 671 grammatical evaluation and selection. We now are now able to unveil the mechanisms giving rise to apparently incongruent results collected with HD patients tested on morphological tasks (Nemeth et al., 2012; Teichmann et al., 2006; Teichmann et al., 2005; Teichmann et al., 2008; Ullman, 2006; Ullman et al., 1997). In fact, the error pattern induced by a selection deficit will depend on the specific properties of the morphological paradigm used to test patients. In English, for instance, there is only one default regular alternation for the past tense. Since the irregular patterns in English are not comparable in their frequency and in their scope to this one regular alternative (Albright and Hayes, 2003), a selection deficit will result in an abnormal rate of selection of the -ed pattern. This is in line with what was observed by 680 Ullman and colleagues (Ullman et al., 1997). More recently, Nemeth and colleagues observed 681 a similar over-regularization pattern in pre-manifest HD subjects tested on the inflection of 682 irregular nouns in Hungarian (Nemeth et al., 2012). Irregular nouns in Hungarian belong to a 683 very restricted class. Alternations within this class are therefore not comparable in terms of 684 frequency and scope to the regular ones. Like in the English past tense paradigms, an incipient 685 selection deficit in this population would thus more likely result in the erroneous selection of 686 the regular alternative instead of the irregular one (i.e. over-regularization error), than the opposite error pattern. French, by contrast, has two regular alternations for the formation of the future tense (first conjugation and second/third conjugation). The default pattern is also 
the most frequent one. In addition French also has a variety of highly restricted irregular

690 alternatives (Meunier \& Marslen-Wilson, 2004) that have a low probability of being

691 considered as part of the set of possible alternatives being considered for each given nonce

692 verb. A patient with a selection deficit would most likely select the default alternative (i.e.

693 first conjugation) for items belonging to the less frequent conjugation class. HD patients will

694 also produce the reverse error pattern - though to a lesser extent - i.e. they will select the less

695 frequent alternative instead of the most frequent one. In fact, this is in line with the response 696 pattern found by Teichmann and colleagues (Teichmann et al., 2006; Teichmann et al., 2005;

697 Teichmann et al., 2008).

698 Our paradigm, with four possible and equally regular alternatives, allows us to show that 699 previously observed error patterns looked as if they were due to a grammatical deficit, 700 because of the specific properties of the morphological paradigms. We could recover the 701 mechanisms through which controls perform the task and compare them to the patients', 702 because we have access to the error pattern of the control population. This was possible 703 because our task was significantly harder than previously used tasks and did not yield ceiling 704 performance in control subjects.

705 Recently it has been proposed that linguistic operations involving movement such as 706 sequential and hierarchical processing in syntax or lexico-semantic mapping of movement in 707 action verbs, are subserved by the frontostriatal network that coordinates motoric information 708 (Birba et al., 2017). Within this neuronal recycling framework (Dehaene \& Cohen, 2007), the 709 different substructures of the striatum may play distinct roles in linguistic operations requiring 710 movement, e.g. with the substantia nigra being involved in functional role assignment (Garcia 711 et al., 2017). In our study, we focused on a linguistic process - a morphological alternation 712 which is not based on movement but on the evaluation and selection of linguistic alternatives 713 and showed that it relies on the caudate. 
714 Our proposal that the striatum holds a role in the selection of linguistic alternatives provides a

715 new framework to reconsider further previous findings of a striatal implication in a coherent 716 way.

717 For instance, research on syntactic processing proposes that the striatum is recruited for 718 syntactic reanalysis, for the resolution of ambiguities and for selecting references in the 719 discourse (Hinzen et al., 2017; Kotz et al., 2003; Mestres-Misse et al., 2012; Sambin et al., 720 2012). In all of these studies, the role of the striatum can be reinterpreted as one pertaining to 721 the selection of one among several syntactic parses. Similarly, in lexical processing the 722 proposed role of the striatum in the inhibition among competing alternatives (Copland et al., 723 2003; Garcia et al., 2017; Longworth et al., 2005) can be restated as a role in the selection 724 among alternatives. A selection deficit could also be at the origin of the rule-learning deficit 725 observed in early HD patients (De Diego-Balaguer et al., 2008), since learning an artificial 726 language requires not only the extraction of regularities from the speech stream, but also the 727 selection of the abstract rule which best characterizes the language to be learned. Finally, our 728 proposal can also account for neuroimaging studies of healthy subjects showing striatal 729 activation in tasks requiring monitoring and controlling the language in use in bilingual 730 speakers (Crinion et al., 2006; Friederici, 2006), as these tasks also involve selecting among 731 several available linguistic constructions.

732 The correlation analysis within the five striatal subregions allowed us show that linguistic 733 performance was not correlated indiscriminately with atrophy in any striatal region. Within 734 the dorsal striatum, the correlation between GM atrophy and linguistic performance was 735 statistically predominant in the caudate nucleus. This result is consistent with the fact that this 736 striatal sub-territory receives projections from the lateral frontal cortex and Broca's area 737 (Alexander et al., 1986). Atrophy in the caudate nuclei thus undermines the selection process 
738 in the linguistic domain. This impairment results in the more frequent selection of suboptimal

739 outcomes (i.e. outcomes with low harmony scores) than in healthy controls.

740 The model used here is necessarily different from those adopted in, e.g., reinforcement

741 learning studies (e.g. Q-learning models (Sutton \& Barto, 1998)), because it was developed in

742 the field of computational linguistics, which deals with very different objectives and modeling

743 constraints. Despite these differences, comparisons across cognitive domains can be fruitfully

744 established, provided equivalent parameters can be identified across the different models.

745 Specifically, the 'deficit' that can be captured by modifying the selection parameter $\lambda$ of our

746 linguistic MaxEntHG is computationally equivalent to the 'deficit' that can be introduced by

747 modifying the choice randomness parameter in a punishment-learning model (Palminteri et

748 al., 2012).

749 Within the broader perspective of the language network, the relationship between cortical 750 language areas and the striatum is analogous to that identified in other domains, between 751 cortical areas and structures of the basal ganglia. The striatum operates as a centralized 752 selection mechanism choosing between alternative options which are assigned weight values 753 in designated connected cortical areas (Alexander et al., 1986; Redgrave, Prescott, \& Gurney, 754 1999), Fig. 4. For instance, in the motor domain, the putamen selects between weighted motor 755 programs evaluated by connected cortical premotor areas (Alexander et al., 1986; O'Doherty 756 et al., 2004). A different corticostriatal circuit is responsible for behavioral goals, that are 757 weighted and assigned reward values in the orbito-frontal cortex and selected by the ventral 758 striatum (Hare et al., 2008; Kable \& Glimcher, 2009; Montague \& Berns, 2002; Padoa759 Schioppa \& Assad, 2008; Rangel et al., 2008). We propose that, through a parallel 760 mechanism, linguistic alternatives evaluated in the left frontal and temporal cortices are 761 selected within the caudate nucleus via the fiber tracts connecting these cortical areas with this 762 subcortical structure. 
Figure 4 Schematic representation of evaluation and selection processes through cortical regions recruited during language processing (BA 44 and 45, which form Broca's Area, and BA 47) - shaded in blue - are involved in the assignment of weight values (harmony values) to linguistic alternatives. Premotor areas (BA 6) involved in the assignment of weight values to motor programs are shaded in pink. The orbito-frontal cortex (BA 11), which assigns weight values to behavioral goals, is shaded in yellow. These cortical areas are connected to striatal subregions (top right) through corticostriatal connections represented schematically by arrows of the corresponding color. The blue arrow represents the pathway linking frontal language regions to the caudate nucleus (shaded in blue), the pink arrow represents the pathway linking premotor regions to the putamen (shaded in pink), the yellow arrow represents the pathway linking orbito-frontal areas to the ventral striatum (shaded in yellow). These striatal subregions are recruited for the Selection of the weighted options through a parallel mechanism: the caudate nucleus selects linguistic alternatives based on the assigned harmony values, the putamen selects among motor plans based on the assigned weighted values, the ventral striatum selects among behavioral goals based on the assigned reward values. (Abbreviations: $\mathrm{BA}=$ Brodmann area).

784 Extensive studies are required to investigate corticostriatal dynamics within the language 785 network. Our proposal is however already supported anatomically by tractographic research mapping corticostriatal connections in the human brain, in both healthy subjects and brain lesioned patients. This research has identified connections between the caudate nucleus and 
Broca's area (BA 44, 45) (Draganski et al., 2008; Ford et al., 2013; Lehericy et al., 2004;

Teichmann et al., 2015). Moreover, recent results on the modification of corticostriatal connections in HD have shown a decrease in bilateral connections from frontal areas to the dorsal striatum (Marrakchi-Kacem et al., 2013). Among the degenerated connections are the ones linking the caudate nucleus with BA 44, 45 and 47. This degeneration may provide the basis for the language impairment observed in patients with early HD in the present study.

Recent reservoir computing models reflecting the contribution of frontal-striatal circuits in language processing (Hinaut \& Dominey, 2013; Szalisznyo, Silverstein, Teichmann, Duffau, \& Smits, 2017) have built on the brain connectivity literature to model the processing of complex syntactic structures and of thematic role assignment within a recurrent network of structurally segregated frontal-striatal circuits. Although both the computational models and the level of linguistic processing are very distinct from the focus of the present study, future research will have to explore to what extent the two lines of research make similar or different 801 predictions - and test them both from a behavioral and from a computational perspective. In addition, other brain regions, e.g. the anterior insula and the ventro-lateral prefrontal cortex have been reported to be involved in selection processes occurring post semantic retrieval, 804 which resolve competition between simultaneously active representations. Activity in these 805 areas was observed during the selection of words (e.g. in verb generation, confrontation naming, word recognition) or visual patterns (Badre \& Wagner, 2005, 2007; Bourguignon,

807 Ohashi, Nguyen, \& Gracco, 2018; Kan \& Thompson-Schill, 2004; Thompson-Schill et al., 808 1998). The relative specificities of the different selection mechanisms and their possible 809 connections remain to be elucidated.

810 Finally, we investigated here the mechanism by which a specific type of linguistic alternatives 811 is selected. Given the generality of the selection mechanism, it seems likely that the dorsal 812 striatum, particularly the caudate nucleus, plays a similar role for other language components. 
813 Furthermore, the observed parallelism between results from within and outside the domain of

814 language raises questions about computational equivalence across domains. We are now in a 815 position to address these questions.

816

817 
818

819

820

821

822

823

824

825

826

827

828

829

830

831

832

833

834

835

836

837

838

839

840

\section{ACKNOWLEDGMENTS}

We thank A. Sliwinski, K. Youssov, L. Lemoine and G. Morgado (CIC) for help with patient assessment, L. Debernard for help with the preprocessing of MRI data, and A. Braatz for help with the drawing of Fig. 4.

\section{DECLARATION OF INTEREST}

The authors declare no conflict of interest.

\section{FUNDING}

This research was supported by: ANR (French Research Agency) grant ANR-11-JSH2-0006 (M.G. and Ch.J.); biomarker program NCT01412125 (Assistance Publique - Hôpitaux de Paris) (A.C.B.L.); Gis-maladies rares A04159JS (Centre de référence maladies rares - maladie de Huntington; Hôpital Henri Mondor, Créteil) (A.C.B.L); NeuroStemcell Consortium FP7 222943 (C.S.); ANR-11-INBS-0011 - NeurATRIS (C.S.); ATIP-Avenir starting grant (St.P.); ANR-10-LABX-0087 IEC and ANR-10-IDEX-0001-02 PSL grants (Département d'Etudes Cognitives of the Ecole Normale Supérieure).

\section{REFERENCES}

Abutalebi, J., Della Rosa, P. A., Gonzaga, A. K., Keim, R., Costa, A., \& Perani, D. (2013). The role of the left putamen in multilingual language production. Brain Lang, 125(3), 307-315. doi:10.1016/j.bandl.2012.03.009 
Albright, A., \& Hayes, B. (2003). Rules vs. analogy in English past tenses: a computational/experimental study. Cognition, 90(2), 119-161. doi:10.1016/S00100277(03)00146-X

Alexander, G. E., DeLong, M. R., \& Strick, P. L. (1986). Parallel organization of functionally segregated circuits linking basal ganglia and cortex. Annu Rev Neurosci, 9, 357-381. doi:10.1146/annurev.ne.09.030186.002041

Ashburner, J., \& Friston, K. J. (2005). Unified segmentation. Neuroimage, 26(3), 839-851.

Badre, D., \& Wagner, A. D. (2005). Frontal lobe mechanisms that resolve proactive interference. Cereb Cortex, 15(12), 2003-2012. doi:10.1093/cercor/bhi075

Badre, D., \& Wagner, A. D. (2007). Left ventrolateral prefrontal cortex and the cognitive control of memory. Neuropsychologia, 45(13), 2883-2901. doi:10.1016/j.neuropsychologia.2007.06.015

Bates D., M. M. M., Bolker B. (2015). Fitting Linear Mixed-Effects Models Using lme4. Journal of Statistical Software, 67(1), 1-48. doi:10.18637/jss.v067.i01 doi:10.1016/j.neubiorev.2017.07.011

Bourguignon, N. J., Ohashi, H., Nguyen, D., \& Gracco, V. L. (2018). The neural dynamics of competition resolution for language production in the prefrontal cortex. Hum Brain Mapp, 39(3), 1391-1402. doi:10.1002/hbm.23927

862 Bybee, J. L. (1995). Regular morphology and the lexicon. Language and Cognitive Processes, 863 $10(5), 425-455$. 
Byrd, R. H., Lu, P., \& Nocedal, J. (1995). A limited memory algorithm for bound constrained optimization. SIAM Journal on Scientific and Statistical Computing, 16(5), 11901208.

867 Cambier, J., Elghozi, D., \& Strube, E. (1979). [Hemorrhage of the head of the left caudate nucleus: disorganization of speech and graphic expression, and disturbances in gestures (author's transl)]. Rev Neurol (Paris), 135(11), 763-774.

Cappa, S. F., Cavallotti, G., Guidotti, M., Papagno, C., \& Vignolo, L. A. (1983). Subcortical aphasia: two clinical-CT scan correlation studies. Cortex, 19(2), 227-241.

Cardebat, D., Doyon, B., Puel, M., Goulet, P., \& Joanette, Y. (1990). [Formal and semantic lexical evocation in normal subjects. Performance and dynamics of production as a function of sex, age and educational level]. Acta Neurol Belg, 90(4), 207-217.

Copland, D. A., de Zubicaray, G. I., McMahon, K., Wilson, S. J., Eastburn, M., \& Chenery, H. J. (2003). Brain activity during automatic semantic priming revealed by eventrelated functional magnetic resonance imaging. Neuroimage, 20(1), 302-310.

Crinion, J., Turner, R., Grogan, A., Hanakawa, T., Noppeney, U., Devlin, J. T., . . Price, C. J. (2006). Language control in the bilingual brain. Science, 312(5779), 1537-1540. doi:10.1126/science.1127761

Damasio, A. R., Damasio, H., Rizzo, M., Varney, N., \& Gersh, F. (1982). Aphasia with 882 nonhemorrhagic lesions in the basal ganglia and internal capsule. Arch Neurol, 39(1), $15-24$.

De Diego-Balaguer, R., Couette, M., Dolbeau, G., Durr, A., Youssov, K., \& Bachoud-Levi, A. C. (2008). Striatal degeneration impairs language learning: evidence from Huntington's disease. Brain, 131(Pt 11), 2870-2881. doi:10.1093/brain/awn242 398. doi:10.1016/j.neuron.2007.10.004 
Demonet, J. F. (1997). Subcortical aphasia(s): a controversial and promising topic. Brain Lang, 58(3), 410-417; discussion 436-458. doi:10.1006/brln.1997.1806

Douaud, G., Gaura, V., Ribeiro, M. J., Lethimonnier, F., Maroy, R., Verny, C., . . Remy, P. (2006). Distribution of grey matter atrophy in Huntington's disease patients: a combined ROI-based and voxel-based morphometric study. Neuroimage, 32(4), 15621575. doi:10.1016/j.neuroimage.2006.05.057

Draganski, B., Kherif, F., Kloppel, S., Cook, P. A., Alexander, D. C., Parker, G. J., . . . Frackowiak, R. S. (2008). Evidence for segregated and integrative connectivity patterns in the human Basal Ganglia. J Neurosci, 28(28), 7143-7152. doi:10.1523/JNEUROSCI.1486-08.2008

Ford, A. A., Triplett, W., Sudhyadhom, A., Gullett, J., McGregor, K., Fitzgerald, D. B., . . . Crosson, B. (2013). Broca's area and its striatal and thalamic connections: a diffusionMRI tractography study. Front Neuroanat, 7, 8. doi:10.3389/fnana.2013.00008

905 Friederici, A. D. (2006). What's in control of language? Nat Neurosci, 9(8), 991-992. doi:10.1038/nn0806-991

Friederici, A. D. (2012). The cortical language circuit: from auditory perception to sentence comprehension. Trends Cogn Sci, 16(5), 262-268. doi:10.1016/j.tics.2012.04.001

Friederici, A. D., \& Gierhan, S. M. (2013). The language network. Curr Opin Neurobiol, 23(2), 250-254. doi:10.1016/j.conb.2012.10.002

911 Friederici, A. D., \& Kotz, S. A. (2003). The brain basis of syntactic processes: functional imaging and lesion studies. Neuroimage, 20 Suppl 1, S8-17. 
913 Garcia, A. M., Bocanegra, Y., Herrera, E., Pino, M., Munoz, E., Sedeno, L., \& Ibanez, A.

914

915

916

917

918

919

920

921

922

923

924

925

926

927

928

929

930

931

932

933

934

935

936

937 (2017). Action-semantic and syntactic deficits in subjects at risk for Huntington's disease. J Neuropsychol. doi:10.1111/jnp.12120

Golden, C. J. (1978). Stroop color and word test. Wood Dale: Stoelting Co.

Goldrick, M., \& Daland, R. (2009). Linking speech errors and phonological grammars: Insights from Harmonic Grammar networks. Phonology(26), 147-185.

Goldwater, S., \& Johnson, M. (2003). Learning OT constraint rankings using a maximum entropy model. Paper presented at the Proceedings of the Stockholm Workshop on Variation within Optimality Theory, Stockholm: Stockholm University, Department of Linguistics.

Gronholm, E. O., Roll, M. C., Horne, M. A., Sundgren, P. C., \& Lindgren, A. G. (2016). Predominance of caudate nucleus lesions in acute ischaemic stroke patients with impairment in language and speech. Eur J Neurol, 23(1), 148-153. doi:10.1111/ene.12822

Hare, T. A., O'Doherty, J., Camerer, C. F., Schultz, W., \& Rangel, A. (2008). Dissociating the role of the orbitofrontal cortex and the striatum in the computation of goal values and prediction errors. J Neurosci, 28(22), 5623-5630. doi:10.1523/JNEUROSCI.130908.2008

Hayes, B., \& Wilson, C. (2008). A Maximum Entropy Model of Phonotactics and Phonotactic Learning. Linguistic Inquiry, 39(3), 379-440.

Hickok, G., \& Poeppel, D. (2007). The cortical organization of speech processing. Nat Rev Neurosci, 8(5), 393-402. doi:10.1038/nrn2113

Hinaut, X., \& Dominey, P. F. (2013). Real-time parallel processing of grammatical structure in the fronto-striatal system: a recurrent network simulation study using reservoir computing. PLoS One, 8(2), e52946. doi:10.1371/journal.pone.0052946 
Hinzen, W., Rossello, J., Morey, C., Camara, E., Garcia-Gorro, C., Salvador, R., \& de DiegoBalaguer, R. (2017). A systematic linguistic profile of spontaneous narrative speech in pre-symptomatic and early stage Huntington's disease. Cortex. doi:10.1016/j.cortex.2017.07.022

Huntington Study Group. (1996). Unified Huntington's Disease Rating Scale: reliability and consistency. Huntington Study Group. Mov Disord, 11(2), 136-142. doi:10.1002/mds.870110204

Kable, J. W., \& Glimcher, P. W. (2009). The neurobiology of decision: consensus and controversy. Neuron, 63(6), 733-745. doi:10.1016/j.neuron.2009.09.003

Kan, I. P., \& Thompson-Schill, S. L. (2004). Selection from perceptual and conceptual representations. Cogn Affect Behav Neurosci, 4(4), 466-482.

Kotz, S. A., Frisch, S., von Cramon, D. Y., \& Friederici, A. D. (2003). Syntactic language processing: ERP lesion data on the role of the basal ganglia. J Int Neuropsychol Soc, 9(7), 1053-1060. doi:10.1017/S1355617703970093

Lehericy, S., Ducros, M., Krainik, A., Francois, C., Van de Moortele, P. F., Ugurbil, K., \& Kim, D. S. (2004). 3-D diffusion tensor axonal tracking shows distinct SMA and preSMA projections to the human striatum. Cereb Cortex, 14(12), 1302-1309. doi:10.1093/cercor/bhh091

Longworth, C. E., Keenan, S. E., Barker, R. A., Marslen-Wilson, W. D., \& Tyler, L. K. (2005). The basal ganglia and rule-governed language use: evidence from vascular and degenerative conditions. Brain, 128(Pt 3), 584-596. doi:10.1093/brain/awh387

Marrakchi-Kacem, L., Delmaire, C., Guevara, P., Poupon, F., Lecomte, S., Tucholka, A., . . . Poupon, C. (2013). Mapping cortico-striatal connectivity onto the cortical surface: a new tractography-based approach to study Huntington disease. PLoS One, 8(2), e53135. doi:10.1371/journal.pone.0053135 
Mattis, S. (1976). Mental status examination for organic mental syndrome in the elderly patient. In B. L. \& K. T.B. (Eds.), Geriatric psychiatry. New York: Grune \& Stratton. Mestres-Misse, A., Turner, R., \& Friederici, A. D. (2012). An anterior-posterior gradient of cognitive control within the dorsomedial striatum. Neuroimage, 62(1), 41-47. doi:10.1016/j.neuroimage.2012.05.021

Meunier, F., \& Marslen-Wilson, W. D. (2004). Regularity and irregularity in French verbal inflection. Language and Cognitive Processes, 19(4), 561-580.

Montague, P. R., \& Berns, G. S. (2002). Neural economics and the biological substrates of valuation. Neuron, 36(2), 265-284.

Moro, A., Tettamanti, M., Perani, D., Donati, C., Cappa, S. F., \& Fazio, F. (2001). Syntax and the brain: disentangling grammar by selective anomalies. Neuroimage, 13(1), 110-118. doi:10.1006/nimg.2000.0668

Nadeau, S. E., \& Crosson, B. (1997). Subcortical aphasia. Brain Lang, 58(3), 355-402; discussion 418-323. doi:10.1006/brln.1997.1707

Nemeth, D., Dye, C. D., Sefcsik, T., Janacsek, K., Turi, Z., Londe, Z., . . Ullman, M. T. (2012). Language deficits in pre-symptomatic Huntington's disease: evidence from Hungarian. Brain Lang, 121(3), 248-253. doi:10.1016/j.bandl.2012.04.001

New, B., Pallier, C., Ferrand, L., \& Matos, R. (2001). Une base de données lexicales du français contemporain sur internet: LEXIQUE. L'Année Psychologique, 101, 447-462.

O'Doherty, J., Dayan, P., Schultz, J., Deichmann, R., Friston, K., \& Dolan, R. J. (2004). Dissociable roles of ventral and dorsal striatum in instrumental conditioning. Science, 304(5669), 452-454. doi:10.1126/science.1094285

Padoa-Schioppa, C., \& Assad, J. A. (2008). The representation of economic value in the orbitofrontal cortex is invariant for changes of menu. Nat Neurosci, 11(1), 95-102. doi:10.1038/nn2020 
Palminteri, S., Justo, D., Jauffret, C., Pavlicek, B., Dauta, A., Delmaire, C., . . Pessiglione, M. (2012). Critical roles for anterior insula and dorsal striatum in punishment-based avoidance learning. Neuron, 76(5), 998-1009. doi:10.1016/j.neuron.2012.10.017

Penney, J. B., Jr., Vonsattel, J. P., MacDonald, M. E., Gusella, J. F., \& Myers, R. H. (1997). CAG repeat number governs the development rate of pathology in Huntington's disease. Ann Neurol, 41(5), 689-692. doi:10.1002/ana.410410521

994 Pinker, S. (1997). How the mind works (1st ed.). New York: Norton.

Plunkett, K., \& Marchman, V. (1993). From rote learning to system building: acquiring verb morphology in children and connectionist nets. Cognition, 48(1), 21-69.

Prince, A., \& Smolensky, P. (1993/2004). Optimality Theory: Constraint interaction in generative grammar. Cambridge: MA: Blackwell.

Rangel, A., Camerer, C., \& Montague, P. R. (2008). A framework for studying the neurobiology of value-based decision making. Nat Rev Neurosci, 9(7), 545-556. doi:10.1038/nrn2357

Redgrave, P., Prescott, T. J., \& Gurney, K. (1999). The basal ganglia: a vertebrate solution to the selection problem? Neuroscience, 89(4), 1009-1023.

1005

Rumelhart, D. E., \& McClelland, J. L. (1986). Parallel distributed processing : explorations in the microstructure of cognition. Cambridge, Mass.: MIT Press.

Sambin, S., Teichmann, M., de Diego Balaguer, R., Giavazzi, M., Sportiche, D., Schlenker,

Stoessl, A. J., Lehericy, S., \& Strafella, A. P. (2014). Imaging insights into basal ganglia function, Parkinson's disease, and dystonia. Lancet, 384(9942), 532-544. 
1013 Sutton, R. S., \& Barto, A. G. (1998). Reinforcement Learning: An Introduction. Cambridge, 1014 MA: MIT Press.

1015 Szalisznyo, K., Silverstein, D., Teichmann, M., Duffau, H., \& Smits, A. (2017). Cortico1016 striatal language pathways dynamically adjust for syntactic complexity: A computational study. Brain Lang, 164, 53-62. doi:10.1016/j.bandl.2016.08.005

Tabrizi, S. J., Langbehn, D. R., Leavitt, B. R., Roos, R. A., Durr, A., Craufurd, D., . . Stout, J. C. (2009). Biological and clinical manifestations of Huntington's disease in the longitudinal TRACK-HD study: cross-sectional analysis of baseline data. Lancet Neurol, 8(9), 791-801. doi:10.1016/S1474-4422(09)70170-X

Teichmann, M., Dupoux, E., Kouider, S., \& Bachoud-Levi, A. C. (2006). The role of the striatum in processing language rules: evidence from word perception in Huntington's disease. J Cogn Neurosci, 18(9), 1555-1569. doi:10.1162/jocn.2006.18.9.1555

Teichmann, M., Dupoux, E., Kouider, S., Brugieres, P., Boisse, M. F., Baudic, S., . . . Bachoud-Levi, A. C. (2005). The role of the striatum in rule application: the model of Huntington's disease at early stage. Brain, 128(Pt 5), 1155-1167. doi:10.1093/brain/awh472

Teichmann, M., Gaura, V., Demonet, J. F., Supiot, F., Delliaux, M., Verny, C., . . BachoudLevi, A. C. (2008). Language processing within the striatum: evidence from a PET

1033 Teichmann, M., Rosso, C., Martini, J. B., Bloch, I., Brugieres, P., Duffau, H., . . Bachoud1034 Levi, A. C. (2015). A cortical-subcortical syntax pathway linking Broca's area and the striatum. Hum Brain Mapp. doi:10.1002/hbm.22769 
Tettamanti, M., Moro, A., Messa, C., Moresco, R. M., Rizzo, G., Carpinelli, A., . . Perani, D. (2005). Basal ganglia and language: phonology modulates dopaminergic release. Neuroreport, 16(4), 397-401.

Thompson-Schill, S. L., Swick, D., Farah, M. J., D'Esposito, M., Kan, I. P., \& Knight, R. T. (1998). Verb generation in patients with focal frontal lesions: a neuropsychological test of neuroimaging findings. Proc Natl Acad Sci U S A, 95(26), 15855-15860.

Tombaugh, T. N. (2004). Trail Making test A and B: Normative Data Stratified by Age and Education. Archives of Clinical Neuropsychology: The Official Journal of the National Academy of Neuropsychologists, 19(2), 203-214.

Ullman, M. T. (2001). A neurocognitive perspective on language: the declarative/procedural model. Nat Rev Neurosci, 2(10), 717-726. doi:10.1038/35094573

Ullman, M. T. (2004). Contributions of memory circuits to language: the declarative/procedural model. Cognition, 92(1-2), 231-270. doi:10.1016/j.cognition.2003.10.008

Ullman, M. T. (2006). Is Broca's area part of a basal ganglia thalamocortical circuit? Cortex, 42(4), 480-485.

Ullman, M. T., Corkin, S., Coppola, M., Hickok, G., Growdon, J. H., Koroshetz, W. J., \& Pinker, S. (1997). A Neural Dissociation within Language: Evidence that the Mental Dictionary Is Part of Declarative Memory, and that Grammatical Rules Are Processed by the Procedural System. J Cogn Neurosci, 9(2), 266-276. doi:10.1162/jocn.1997.9.2.266

Vonsattel, J. P., Myers, R. H., Stevens, T. J., Ferrante, R. J., Bird, E. D., \& Richardson, E. P., Jr. (1985). Neuropathological classification of Huntington's disease. J Neuropathol Exp Neurol, 44(6), 559-577. 
1060 Wechsler, D. (1981). Wechsler adult intelligence scale - revised manual. New York:

1061

Psychological Corporation.

1062 


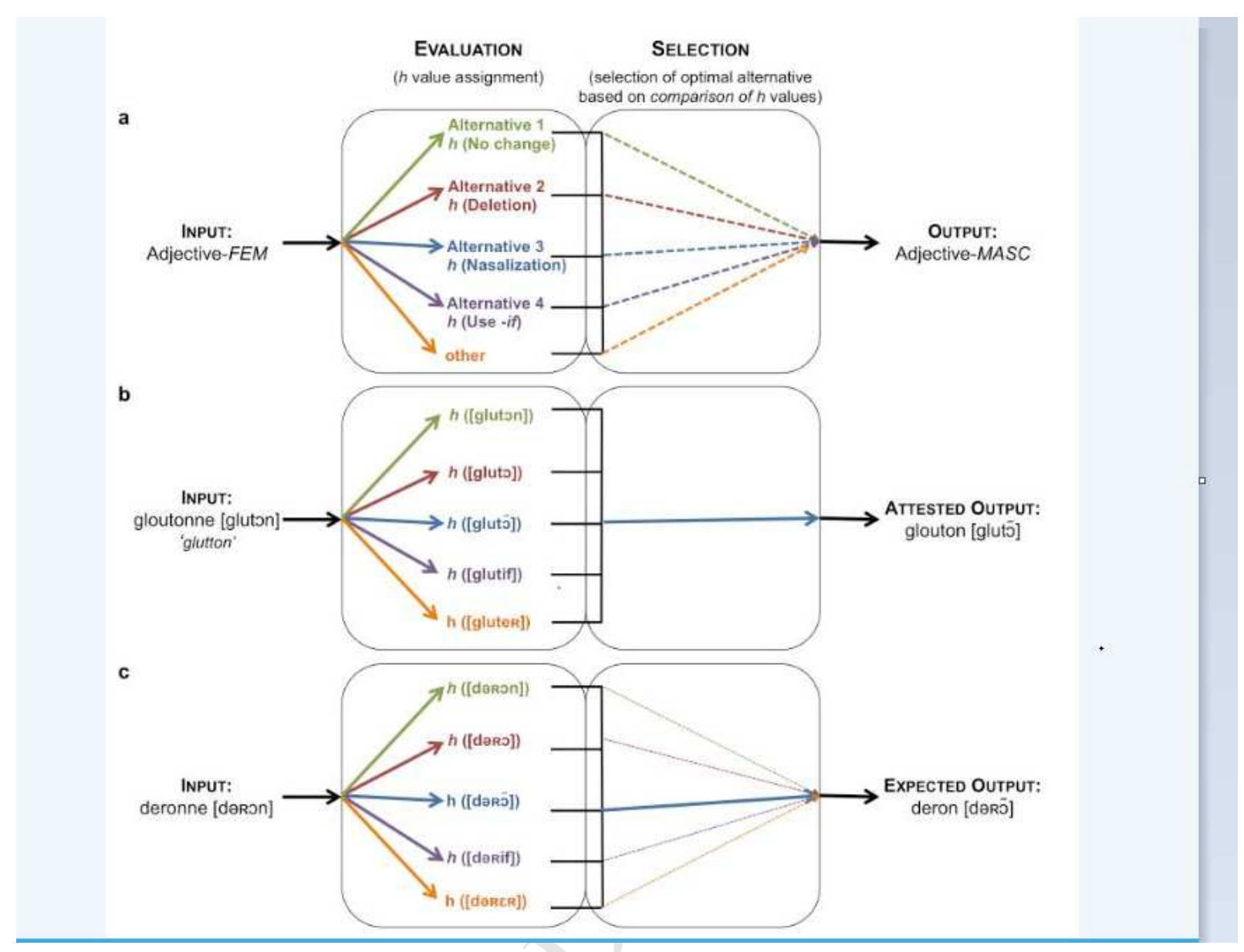




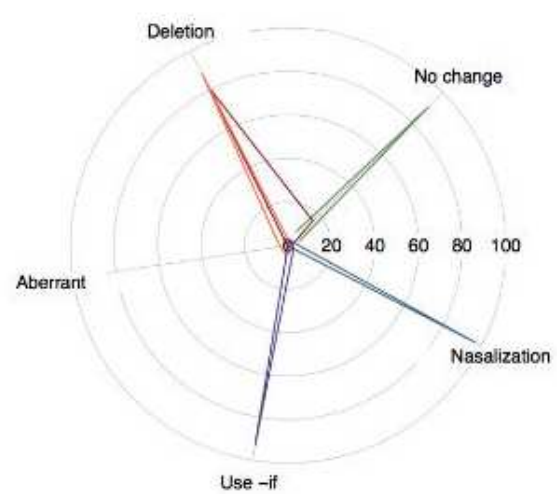

Use -if b

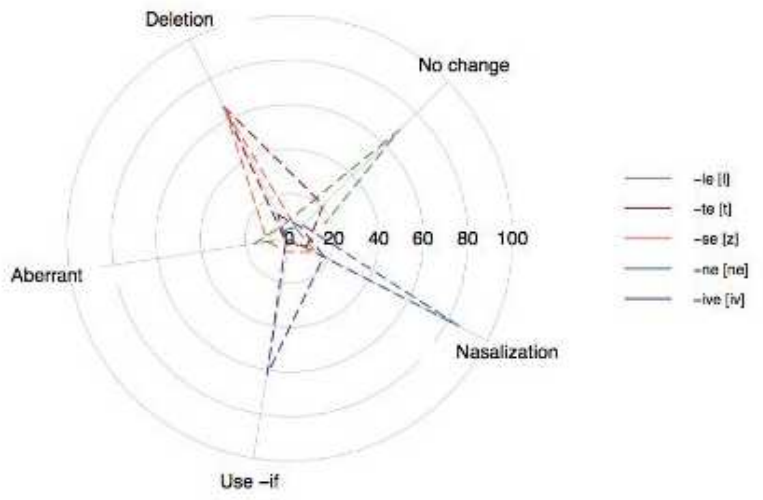



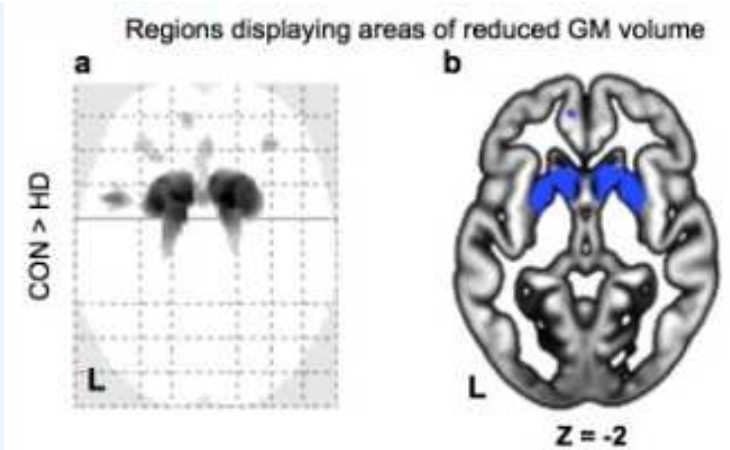

Correlation with linguistic performance

c

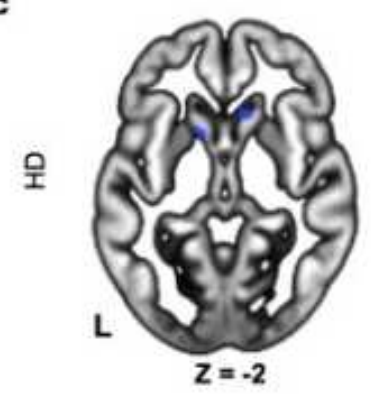

d
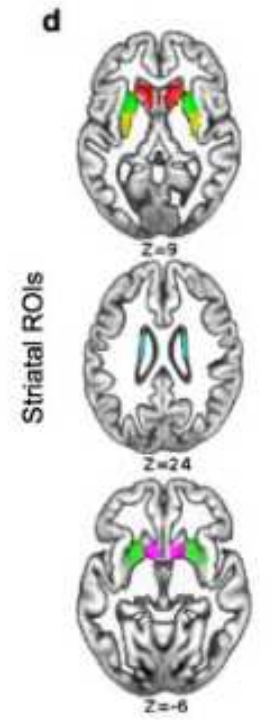

e
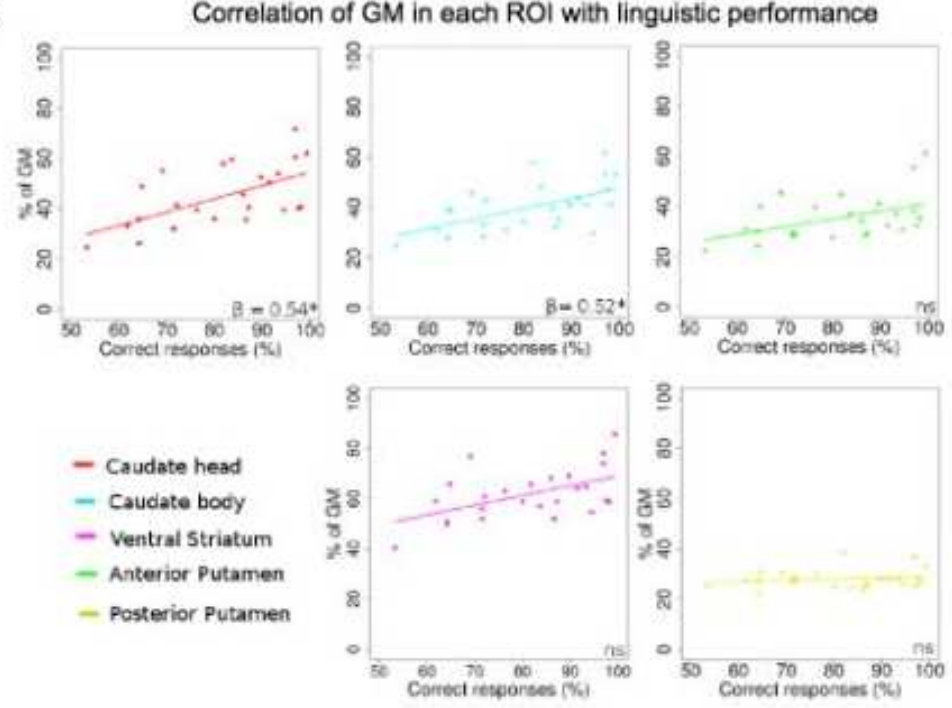


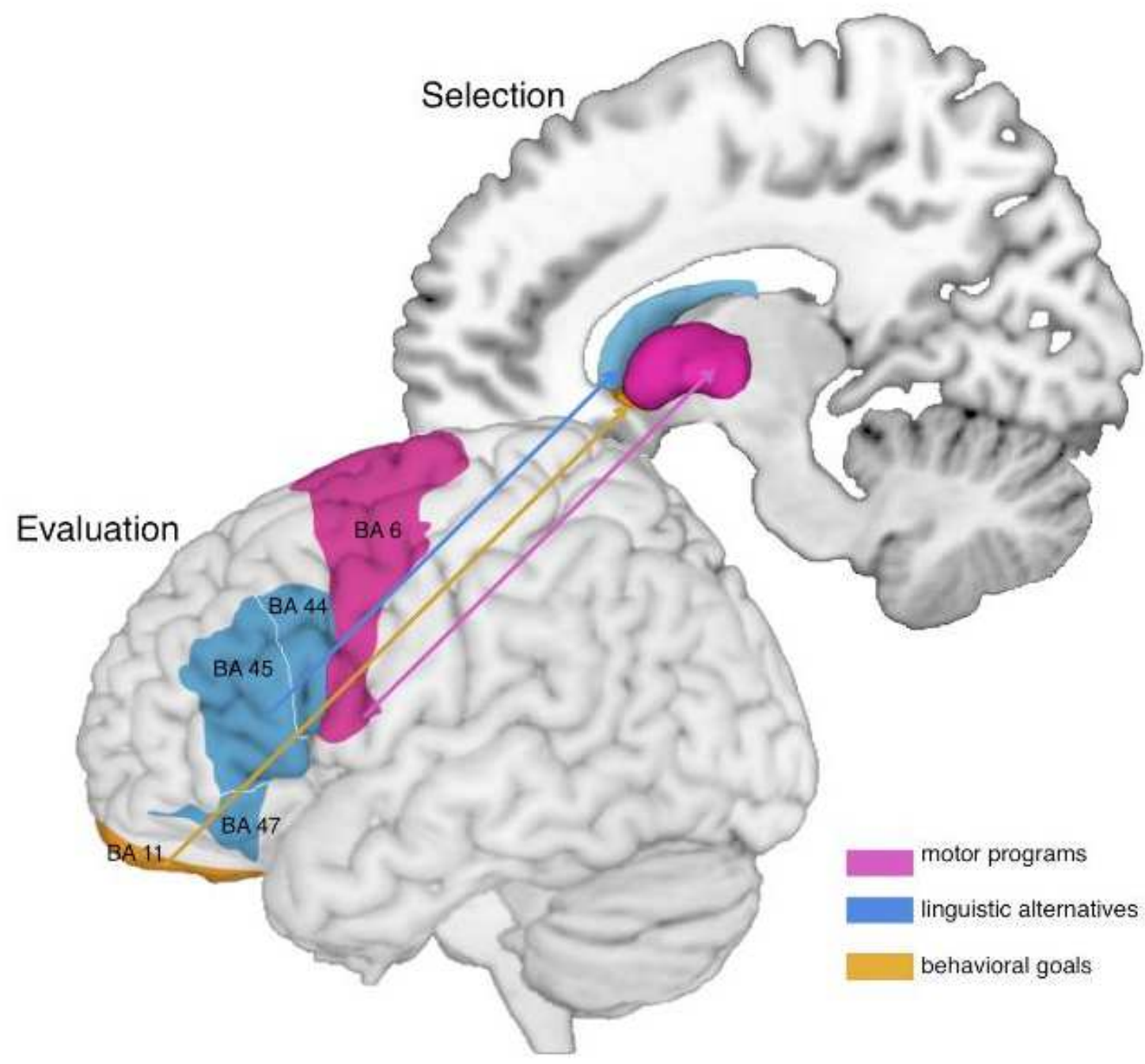

